\title{
Análisis de una relación (in)visibilizada en los contextos de Formación Docente Inicial: Una reflexión epistemológica, teórica y metodológica desde una perspectiva de género.
}

\author{
Analysis of a relation (in)visible in the contexts of Initial Education Formation: An epis- \\ temological, theoretical and methodological reflection from a gender perspective \\ Análise de uma relação (in)visibilizada nos contextos da Formação Inicial da Profes- \\ sores: Uma reflexão epistemológica, teórica e metodológica da uma perspectiva da \\ género
}

\section{Verónica Lizana M.}

El Colibrí \# 91 Depto. 31. La Florida. Santiago de Chile. CP. 8311436. Telf.: 06 8247149. Correo electrónico: valizana@gmail.com

\begin{abstract}
RESUMEN
Este documento presenta una reflexión epistemológica, teórica y metodológica sobre el estudio colectivo de casos: Una relación (in)visibilizada en los contextos de Formación Docente Inicial: Una configuración de la Identidad Profesional Docente desde una perspectiva de género. Actualmente, esta Tesis Doctoral se encuentra en trabajo de campo, por lo que la investigadora ha negociado con los/las participantes, el rol y las funciones asumidas en cada escenario de estudio. Asimismo, ha evaluado la coherencia entre los horizontes de sentido de esta investigación, y las fases, procedimientos y actividades implementadas en el transcurso del terreno. Como también, ha puesto en permanente discusión su pertinencia con los criterios de validez, confiabilidad y éticos.

Palabras clave: formación docente inicial, reflexión epistemológica, teórica y metodológica, perspectiva de género.
\end{abstract}

\begin{abstract}
This document presents an epistemological, theoretical and methodological reflection on the collective study of cases: A relation (in)visible in the contexts of Initial Educational Formation: A configuration of the Educational Professional Identity from a gender perspective. At the moment, this Doctoral Thesis is in work of field, reason why the investigator has negotiated with the participants, the roll and the functions assumed in each scene of study. Also, she has evaluated the coherence between the horizons of sense of this investigation, and the phases, procedures and activities implemented in the course of the land. Like also, she has put in permanent discussion his relevance with the criteria of validity, trustworthiness and ethical.

Key words: initial educational formation, epistemological, theoretical and methodological reflection, gender perspective.

\section{RESUMO}

Presentes deste original uma reflexão epistemológica, teórica e metodológica no estudo coletivo dos casos: Uma (in) visibilizada da relação nos contextos da Formação Inicial de Professores: Uma configuração da Identidade Profissional Educacional de uma perspectiva da género. No momento em que, esta Tese Doutoral está no trabalho do campo, a razão pela qual o investigador negociou com participantes, o rolo e as funções supor em cada cena do estudo. Também, avaliou a coerência entre os horizontes do sentido desta investigação, e as fases, os procedimentos e as atividades executados no curso da terra. Como também, põr na discussão permanente sua relevância com os critérios da validez, da fiabilidade e de ético.
\end{abstract}

Palavras chave: formação inicial da professores, reflexão epistemológica, teórica e metodológica, perspectiva da género. 


\section{INTRODUCCIÓN}

En términos generales, las perspectivas epistemológicas refieren a los fundamentos teóricos y metodológicos adoptados por una comunidad científica o equipo de investigadores/as, la que históricamente ha establecido las teorías, definiciones, funciones, fases y criterios sobre el ejercicio de la ciencia. Desde una o varias disciplinas académicas, estas personas han configurado una episteme polifacética, un cuerpo (des)ordenado, (in) estable e (in)seguro de saberes, habilidades y actitudes, a partir de ciertas visiones de mundo; modelos (in)formales de pensamiento; conjunto de leyes, preceptos o reglas; y métodos de intervención (Bunge, 1978; Abbagnano, 2007).

Por derecho natural, legal o consuetudinario, estos nichos (inter)disciplinares han generado ciertas condiciones materiales y simbólicas para (re)producir, distribuir y aplicar el conocimiento, desde donde se infieren los puntos de inflexión de la indagación científica, es decir, aquellas formulaciones, presunciones, pretensiones y/o disposiciones que procuran dilucidar cuál es su naturaleza, estructura y límite; cuáles son sus marcos conceptuales, procedimentales y actitudinales; cuáles son sus ejes, elementos y procesos constitutivos; cómo se demarcan sus criterios de validez y confiabilidad; cómo los/las sujetos se relacionan con aquello que pretenden conocer-aprehender-(re)construir, entre otras. En el corto, mediano y largo plazo, estos parámetros van asentando el estatus o valor preposicional del conocimiento alcanzado, cuyos criterios de verdad son dimensionados o comparados, tanto por las mutaciones cualitativas o cambios significativos de sus propiedades inherentes, como por los saltos cuantitativos o impactos medibles de sus resultados, utilidades y contribuciones (Bernal \& Zúñiga, 2007; Lizana, 2009).

Por consiguiente, este estudio adopta como horizonte de sentido el construccionismo epistemológico. Esta perspectiva concibe a la ciencia como una actividad humana, que por una parte, está condicionada y/o tensionada por momentos históricos, contextos socioculturales, intereses económicos, políticos e ideológicos; y, por otra, está permeada y/o mediatizada por las creencias, valores, (pre)juicios, (re)acciones y expresiones de sus actores protagónicos. Con relativa homogeneidad o heterogeneidad, una comunidad científica o equipo de investigadores/as está conformado por profesionales organizados dentro de un contexto institucional, los que a partir de ciertos fundamentos teóricometodológicos y sistemas de monitoreo-control intentan delimitar un objeto de estudio; resolver un problema de investigación; o enfrentar un hecho y/o fenómeno de la realidad (Sandín, 2003; Corbetta, 2007).

En este sentido, el ejercicio de la ciencia procura visibilizar las condiciones materiales y simbólicas de (re)producción, distribución y aplicación del conocimiento, cuyo conjunto de saberes, habilidades y actitudes configura los puntos de (des)articulación, esferas temáticas y nudos problemáticos de la experiencia de conocer-aprehender-(re) construir. Habitualmente, estas circunstancias categorizan, modulan o asocian ciertos horizontes de sentido a la estructura psíquica sobre las imágenes-apariencias-(re)acciones de sí mismo/a; a la estructura comprensiva sobre los modos de saber-ser, saber-convivir, saber-conocer y saber-hacer; y a la estructura interactiva sobre la matriz significativa del contexto histórico y sociocultural (Bernard, 1997; Lizana, 2009).

De este modo, la indagación científica intenta develar cuáles son los puntos de inflexión de la experiencia de conocer-aprehender-(re)construir de los/las sujetos de estudio; cuáles son los horizontes de sentido que se encuentran encapsulados en su estructura psíquica, 
comprensiva e interactiva; o cómo estos significados, valores o verdades conforman sus procesos de subjetivación, objetivación e intersubjetivación. Por lo tanto, este enfoque se encuentra comprometido con los afanes de libertad, democracia y justicia social, lo que implica (re)significar sus experiencias identitarias relativas a las relaciones de género y sus operaciones representacionales asociadas a la división sexual del trabajo. Se trata de una construcción cultural del conocimiento, a fin de que los actores sociales potencien sus facultades reflexivas y dialógicas ante la misma (Abbagnano, 2007, Lizana, 2007) .

Asimismo, se entiende que una comunidad científica o equipo de investigadores/as asume o comparte ciertas perspectivas ontológicas, epistemológicas y metodológicas, cuyas preguntas centrales se sintetizan o traducen de la siguiente manera: cuál es la realidad histórica, cultural, social, económica, política e ideológica de aquello que se pretende conocer-aprehender-(re)construir; cuál es la relación de conocimiento que se establece entre el/la que conoce y lo conocido-aprehendido-(re)construido; y cómo deberían proceder o actuar los/las científicos/as o investigadores/as para (re)construirlo, distribuirlo y aplicarlo. Estas respuestas son indispensables a la hora de pensar en la ontogenia y filogenia de una o varias disciplinas académicas, puesto que en ellas reposan las características esenciales, premisas (in)concientes o nociones fundamentales sobre la realidad estudiada, el/la sujeto de estudio y el objeto cognoscible (Bunge, 1978, Cherryhomes, 1999; Castro, 2004).

Según tales ideas, la dimensión ontológica describe la naturaleza inteligible de un objeto, problema, hecho y/o fenómeno de la realidad sociocultural. Una (re)construcción individual y colectiva, una (re)elaboración sistemática o (re)acción dinámica, entre las manifestaciones de lo cognoscible y las imposiciones, sujeciones y disciplinamientos del contexto local y específico. La dimensión epistemológica refiere a la naturaleza genérica de la relación de conocimiento, la que establece ciertos ejes, elementos y procesos a sus procesos de (re)producción, distribución y aplicación del conocimiento. Esta experiencia procura recuperar los dispositivos de los nichos (inter)disciplinares y las epistemes de los actores sociales, dejándose afectar mutuamente ante aquello que se pretende conocer-aprehender-(re)construir. Por último, la dimensión metodológica se centra en la naturaleza estratégica del método, en los códigos éticos, conceptuales, procedimentales y actitudinales, que son diseñados, implementados y legitimados por una comunidad científica o equipo de investigadores/as. Estos métodos, estrategias, técnicas e instrumentos les permiten describir, interpretar y analizar sus conclusiones, resultados y/o hallazgos de investigación (De Gialdino, 1992; Ruiz, 1999; Sandín 2003).

A partir de la yuxtaposición de la dimensión ontológica, epistemológica y metodológica se pueden comprender las prácticas discursivas y no discursivas de los/las sujetos de estudio, las que obedecen a un conjunto de reglas históricas, culturales, sociales, económicas, políticas, ideológicas, geográficas, etc. Estas condiciones de (im)posibilidades por una parte configuran las coordenadas tiempo-espacio, la época, el campo o área de la función enunciativa. Y por otra, definen las relaciones de poder, los dispositivos extrínsecos e intrínsecos del ejercicio en sí mismo, cuyo juego estratégico lo (des)articula con otras maneras de ser y estar en el mundo. Según Foucault (2006), una investigación sobre las expresiones lingüísticas y acciones comunicativas de los actores sociales describe las regularidades subyacentes en sus procesos de objetivación, subjetivación e intersubjetivación; o caracteriza las racionalidades coexistentes en sus modos de saberser, saber-convivir, saber-conocer y saber-hacer. De modo que el carácter recurrente y 
sistemático de cada dominio específico devela la libertad con la que las personas piensan y actúan en este sistema de prácticas.

Asimismo, se hace necesario considerar el eje del saber de las prácticas discursivas y no discursivas; el eje del poder o las relaciones (in)directas con los/las otros/as; y el eje de la ética o las relaciones del individuo consigo mismo. El entrelazamiento de dichos ejes constituye al ser humano en sujeto de conocimiento; sujeto social, ético y jurídico; y sujeto conciente de sí y de los/las otros/as. Por lo que establece el dominio cultural de sus experiencias u organiza sus formas de pensamiento, según la tipología de ciertas normatividades e (inter)subjetividades. Al respecto, el pensamiento se concibe como una (re)acción, en la medida que ésta instaura el juego de lo verdadero y de lo falso; la aceptación o rechazo de la norma-regla; y la relación de sí con los demás (Castro, 2004; Foucault, 2006).

Por consiguiente, las expresiones lingüísticas y acciones comunicativas de los/las sujetos de estudio conforman ciertos distanciamientos, proximidades e (in)dependencias, tanto hacia el interior de sus instituciones, comunidades o equipos de trabajo, como hacia las organizaciones y colectividades de la sociedad civil. En este escenario de reciprocidades, responsabilidades y compromisos se toman decisiones sobre la realidad estudiada; se negocian los roles y las funciones de las personas involucradas; y se interviene la naturaleza inteligible del objeto cognoscible. Del mismo modo, se entiende que una construcción cultural del conocimiento puede estar de frente o a espaldas de los seres humanos. Por ello, esta investigación procura analizar las modalidades externas de su contexto normativo, alternativo o disruptivo; las proposiciones de verdad de sus medidas transitorias, complejas e (inter)disciplinarias; y las propiedades inherentes de sus campos de (im)posibilidades. (Lizana, 2008).

Asimismo, este estudio advierte que la experiencia de conocer-aprehender-(re) construir no está al margen de los cambios, crisis, contingencias y emergencias de un mundo capitalista-consumista y globalizado-pluralista; ni es indiferente a las múltiples maneras de describir, interpretar y analizar una realidad local y específica. Por lo que procura desmenuzar la complejidad del mundo real, donde las necesidades, intereses y expectativas de los actores sociales se juegan entre las exigencias de una sociedad del conocimiento, y los derechos y obligaciones de un Estado-Nación. En esta diversidad de perspectivas coexisten los/las ciudadanos/as del mundo, cuyos medios audiovisuales y recursos informático-tecnológicos les permiten ampliar el espectro de sus redes sociales, interconectando diariamente a niños, niñas, jóvenes y adultos/as con distintas comunidades virtuales. Si bien los/las habitantes del ciberespacio han generado una proliferación de significados, valores o verdades; una mayor preocupación por la conciencia ecológica; o una cierta sensibilidad hacia las mutaciones del Estado-Bienestar, los lenguajes digitales de la sociedad civil no se han democratizado, puesto que su inteligibilidad cultural aún depende de las políticas de clase, género y etnia (Cherryholmes, 1999; Giroux, 2004).

Por consiguiente, el construccionismo epistemológico procura describir, interpretar y analizar cómo los seres humanos, (re)construyen y comparten múltiples y complejos horizontes de sentido en relación a un mismo objeto de estudio; problema de investigación; hecho y/o fenómeno sociocultural. Es más, los/las sujetos implementan un conjunto de expresiones lingüísticas y acciones comunicativas para comprender, explicar y legitimar estos significados, valores o verdades. Los que emergen mediante las relaciones interpersonales o cobran sentido en las interacciones ejercidas recíprocamente a modo 
de diálogo. En estos intercambios significativos se generan las prácticas discursivas y no discursivas de los actores sociales, cuyos procesos de individualización y socialización están circunscritos en un sistema de organización histórico-cultural, socio-económico y político-ideológico. Con diversos matices, estas formas de administración regulan los medios de (re)producción, distribución y aplicación del conocimiento, por lo que no siempre promueven o favorecen la igualdad de oportunidades o el desarrollo integral de las personas (Ruíz, 1999; Sandín, 2003).

En sentido absoluto, los saberes, habilidades y actitudes de los/las sujetos de estudio están entrelazados al campo de (im)posibilidades de las condiciones sociales, las que estructuran progresivamente los macro y micro niveles de la experiencia de conoceraprehender-(re)construir. Por consiguiente, la calidad y equidad de estas condiciones afectan los estados internos y externos de las personas, e influyen en sus aptitudes, facultades o disposiciones hacia la (re)construcción del conocimiento. Una actividad personal, social, formativa y profesional, que se organiza a partir de ciertas cosmovisiones o maneras de ser y estar en el mundo. Esta situación indispensable o circunstancia elemental coexiste en las formalidades, normatividades, procedimientos e intervenciones, que adopta dicha actividad.

Desde esta perspectiva, la intencionalidad de conocer-aprehender-(re)construir o el ejercicio de la (re)significación remite a los procesos de subjetivación o estructuración psíquica sobre las imágenes-apariencias-reacciones de sí mismo/a; a los procesos de objetivación o estructuración comprensiva sobre los modos de saber-ser, saber-convivir, saber-conocer y saber-hacer; y a los procesos de intersubjetivación o estructuración interactiva sobre la matriz significativa del contexto histórico y sociocultural. Por consiguiente, se entiende que estos procesos se desencadenan o son gatillados cuando los seres humanos estructuran psíquica, comprensiva e interactivamente sus experiencias identitarias y operaciones representacionales. Una dimensión personal, social, formativa y profesional, que configura-circunscribe; posiciona-demarca; regula-normaliza; e identifica-diferencia, "una ontología de sí mimo/a en relación al poder, la verdad y la moral" (Bernard, 1997; León \& Montero, 2002; Abbagnano, 2007).

Según el psicoanálisis, la dimensión personal distingue tres planos distintos en la individualización del sujeto, pero en sus comportamientos individuales e interacciones sociales se encuentran tácitamente entrelazadas. En el centro de la personalidad están las premisas concientes del Yo, cuyos significados, valores o verdades se creen independientes y dueñas de sí mismas. Debajo de estas descansan las premisas inconcientes del Ello, un campo de pulsiones instintivas, tendencias involuntarias, impulsos intuitivos o fuerzas psíquicas que el Yo no domina. Ante el cual se oponen las premisas represivas del Súper Yo, donde se halla la internalización o introyección de las coerciones socioeducativas (Neri, 1997; Abbagnano, 2007; Lizana, 2009).

En otras palabras, el Yo como organización y conocimiento procura servir a los fines materiales y simbólicos de la realidad; el Ello está constituido por los impulsos múltiples de la libido, una energía originaria y creativa dirigida constantemente hacia el placer; y el Súper Yo como conciencia moral o inconciente colectivo refiere al conjunto de prohibiciones y censuras inculcadas de manera privada-individual y pública-social, las que se acumulan y consolidan a lo largo de la vida de las personas. Estos procesos psíquicos desencadenan los siguientes fenómenos: los sueños o expresiones deformadas y simbólicas de los deseos reprimidos; los actos fallidos, lapsus o equivocaciones 
aparentemente atribuidas al azar; los síntomas de una perturbación mental, cuyos signos sustituyen una frustrada satisfacción de un instinto o son el resultado de una represión; la sublimación o transferencia de los impulsos instintivos a otros objetos cognoscentes; los complejos o mecanismos asociativos, etc. Estos fenómenos caracterizan el juego de fuerzas u oposiciones entre el sentimiento de comunidad y la voluntad de poder, puesto que al ligar a los individuos a un contexto local y específico, éste les impone una política sobre su identificación-diferenciación de clase, género y etnia (Neri, 1997; Abbagnano, 2007; Lizana, 2009).

Por lo tanto, la dimensión personal describe la individualización de un sujeto o la personalidad de un individuo, una (re)construcción compleja, arquetípica y dinámica, que varía según las distintas etapas del desarrollo psíquico, biológico y relacional. Esta singularidad o individualidad se expresa en un proyecto de vida, entendiéndolo como un eje articulador o vínculo unificador, que le proporciona una cohesión a las unidades de sentido formadas para sí mismo/a, o una integración de las premisas (in)concientes y represivas sobre sus imágenes-apariencias-reacciones. De este modo, el ejercicio de la (re)significación implica revisar los proyectos de vida en primera persona singular, teniendo presente que en toda visibilización del Yo subyacen "las trampas del enemigo interno", llámese actos fallidos del dinamismo inconciente o fuentes de conflicto de la autorregulación coercitiva.

Si bien, estos mecanismos participan en la configuración psíquica, comprensiva e interactiva de las experiencias identitarias y operaciones representacionales de los/las sujetos de estudio. Los significados, valores o verdades asociadas a estos procesos psicológicos se establecen mediante ciertos criterios convencionales, y la personalidad se constituye a partir de una serie de identificaciones-diferenciaciones dentro de un contexto histórico y lingüístico. Estas pautas psicosociales le permiten a las personas conocer-aprehender-(re) construir un aspecto, prioridad o atributo de un/a otro/a significativo/a, los que son asimilados, superados y transformados, total o parcialmente, tanto para acercarse o distanciarse del modelo que este le proporciona, como para alcanzar y conquistar la propia autonomía. La reciprocidad y contradicción entre estos modelos conforma la contingencia, transitoriedad y recursividad de la identidad personal, una (re)significación del Yo como (re) construcción de la diferencia y de los proyectos vitales, lo que implica autodeterminación y emancipación ante las modalidades externas, proposiciones de verdad y propiedades inherentes del saber-ser (Harré \& Roger, 1992; Lizana, 2009; Consuegra, 2010).

Por su parte, la dimensión social describe la socialización de un sujeto o las interacciones sociales de un individuo, cuyas condiciones de existencia y campos de (im) posibilidades intervienen en la formación, dinámica y transformación de sus grupos de referencia. Estas comunidades o colectividades estructuran la vida material y simbólica de las personas, incorporándolas a las redes primarias y secundarias de una sociedad. Las primeras refieren a los grupos familiares, ya sean estos nucleares, extendidos, monoparentales, monomaternales, heterosexuales, homosexuales, urbanos, rurales u hogares sustitutos, instituciones privadas o gubernamentales, que protegen a los niños, niñas y jóvenes en situación de riesgo, violencia, abuso o abandono. En estos casos, cada integrante se conoce entre sí; mantiene relaciones personales o vínculos profundos con los demás; y define, de manera vertical u horizontal, su estructura sociocultural, organización jerárquica, funcionamiento económico y patrones ideológicos. Habitualmente, los grupos primarios tienen un número reducido de miembros, los que con relativa armonía y 
flexibilidad cultivan el contacto directo entre los mismos, potenciando la personalidad de cada individuo contra la amenaza de su masificación y uniformidad. Según las condiciones sociales y posibilidades de la comunicación, los lazos afectivos "cara a cara" generan interacciones más numerosas, nutritivas y espontáneas, entrelazando (in)concientemente las emociones, sentimientos, afectos o rechazos personales con ciertas imágenes de autoridad y/o figuras de apego (Mialaret, 1984; Harré \& Roger, 1992; Consuegra, 2010).

En cambio, las redes secundarias describen la inserción (in)formal de los individuos a otros grupos sociales, entiéndase instituciones educativas, terapéuticas, recreativas, religiosas, esotéricas, políticas, laborales, sindicales, vecinales, etc. Por lo general, estas comunidades son numerosas y la relación entre sus miembros es indirecta, puesto que está condicionada por el sistema organizacional, estructura de funcionamiento y niveles de cohesión del grupo. Si bien, este contacto puede ser real, concreto, natural, ocasional, artificial, virtual, individual, grupal, duradero y/o temporal, las actitudes comunes y recurrentes adoptadas por una colectividad, sus escenarios, protagonistas, procesos, medios y vías de comunicación, evidencian el campo de las relaciones subjetivas, objetivas e intersubjetivas entre los/las sujetos (Mialaret, 1984; Harré \& Roger, 1992; Consuegra, 2010).

Por consiguiente, las redes primarias y secundarias de una sociedad intervienen en la formación, dinámica y transformación de los grupos de referencia de las personas. No obstante, la incorporación o pertenencia a estas redes sociales otorga o proyecta una cierta seguridad a sus condiciones de existencia y campos de (im)posibilidades, éstas le atribuyen al grupo una preexistencia independiente, como si tuviera una realidad aparente o anterior de quienes lo conforman. Por ello, se entiende que la cohesión es un elemento central en la individualización-socialización de un sujeto, permitiéndole a sus grupos primarios y secundarios mantenerse unidos en el corto, mediano o largo plazo. A partir de estos hechos o fenómenos sociales, los individuos se transforman en actores protagónicos, y configuran la estructura psíquica, comprensiva e interactiva de sus experiencias identitarias y operaciones representacionales. Estos horizontes de sentido son accesibles a la comprensión a través de las motivaciones personales, sociales, formativas y profesionales de los/las sujetos, cuyas actitudes e intenciones mantienen un equilibrio (dis)continuo entre las relaciones de poder establecidas por una sociedad; y los cambios culturales adoptados por los modos de vida, por los grados de participación y movilización en esta (Fraser, 1997; Rawls, 1998).

Según Rawls (2002), lo social refiere a un sistema de justicia, equidad y cooperación, cuya sujeción y sucesión en el tiempo se (re)construye de generación en generación. En este sentido, la cooperación describe los procesos, medios y productos de una actividad o experiencia socialmente compartida y coordinada, la que es el resultado de un conjunto de reglas y procedimientos, o deriva del reconocimiento público de quienes cooperan. Esta idea circunscribe los principios de justicia y los términos de equidad en la base estructural de una sociedad, ya que por una parte expresa los derechos y deberes fundamentales de los grupos humanos que han aprendido a obrar en conjunto. Y, por otra, especifica los beneficios producidos por el esfuerzo individual y colectivo, en provecho de ser distribuidos equitativamente de una generación a la sucesiva.

Independientemente de las relaciones con el Estado-Nación y su organización política, la socialización implica un proceso material, intersubjetivo y comunicativo, que promueve o favorece las condiciones necesarias para el desarrollo integral de los actores sociales. De manera que la mutua cooperación entre los grupos de referencia, entre estos y grupos 
diferentes potencie la utilidad práctica de sus vínculos y la realización de sus proyectos individuales y colectivos. Por ello, la identidad social refiere a la resignificación del Yo como (re)construcción de los derechos humanos y de las obligaciones ciudadanas, lo que implica compromiso y responsabilidad ante las modalidades externas, proposiciones de verdad y propiedades inherentes del saber-convivir.

Por su parte, la dimensión formativa describe la formación personal, formativa, profesional y social de una persona, término que se contrapone al de instrucción, ya que su preocupación no solo radica en la calidad y equidad de los procesos de (re)producción, distribución y aplicación del conocimiento, sino que, además, procura integrarlos en el desarrollo psíquico, biológico y relacional de un individuo. A fin de que estos saberes, habilidades y actitudes formen parte de su personalidad, la que se expresa como singularidad-totalidad en las instituciones e interacciones socioeducativas. En otras palabras, se trata de una educación integral, rigurosa, sistemática, progresiva e (inter)disciplinaria, que está comprometida o "se hace cargo" de la individualización y socialización de sus actores protagónicos. A partir de estas condiciones materiales y simbólicas, la formación como proceso de humanización le permitirá actuar con responsabilidad en su contexto local y específico; formarse permanentemente a lo largo de su vida; y adaptarse a las incesantes necesidades, intereses y expectativas de su sociedad. (Cárdenas, 2001; Rodríguez, 2003; Bolívar 2007; Abbagnano, 2007).

En términos generales, las instituciones educativas o grupos secundarios están encargados de transmitir, de generación en generación, los significados, valores o verdades aceptadas por una cultura. Como también tienen como propósito (re)construir la existencia, sobrevivencia y comportamiento de la sociedad civil, de modo que las personas puedan vivir en una forma más o menos ordenada y pacífica. Para una comunidad, los procesos formativos garantizan el carácter continuo e inmutable de lo sagrado, por lo que los hechos y/o fenómenos educativos deben proteger, mantener o conservar, a través del tiempo, su patrimonio cultural, social, político, moral, ético, espiritual, religioso, etc. Pero también, estos procesos avalan el carácter discontinuo y movible de lo nuevo, ya que una constante del devenir humano es afrontar situaciones distintas, cambiantes y complejas. Las que tienden a flexibilizar y transformar las orientaciones socioeducativas mediante la iniciativa, voluntad, creatividad e innovación de los individuos. En ambos casos, la dimensión formativa se concibe como un derecho fundamental de la persona, que evidencia los nexos entre los principios de la democracia, libertad, justicia, equidad y cooperación de los contextos socioeducativos y los términos de la dignidad, especificidad y potencialidad de sus actores protagónicos (Cárdenas, 2001; Rodríguez, 2003; Bolívar 2007; Abbagnano, 2007).

Desde la construcción epistemológica de esta investigación, se entiende que la formación personal, social, formativa y profesional configura los campos (inter)disciplinarios de la pedagogía. Así como la naturaleza inteligible, genérica y estratégica de su objeto de estudio, es decir, los hechos y/o fenómenos educativos. Un conjunto de experiencias, temáticas, problemáticas y procedimientos, que se nutre de los múltiples enfoques de sus ciencias auxiliares. Estos horizontes de sentido subyacen en la triada del discurso pedagógico o mantienen una coexistencia en la formación antropológica relativa al contexto sociocultural de los actores educativos; en la formación teleológica concerniente a los fines o propósitos de las instituciones educativas; y en la formación metodológica relacionada con las modalidades didácticas adoptadas para las prácticas de enseñanza y procesos de aprendizaje (Aguerrondo, 2005; Trilla, 2007). 
En sentido individual y social, la pedagogía procura describir, interpretar y analizar la complejidad de la educación, cuyas manifestaciones materiales y simbólicas mantienen una inexorable conexión con los procesos de subjetivación, objetivación e intersubjetivación de los actores educativos. Este armazón (inter)disciplinario estructura las dimensiones de la formación, "una ontología de sí mimo/a en relación al poder, la verdad y la moral", que configura-circunscribe; posiciona-demarca; regula-normaliza; e identifica-diferencia los medios de (re)producción, distribución y aplicación del conocimiento. De esta manera, las macro y micro políticas constituyen el fenómeno socioeducativo, es decir, la formalidad de sus espacios institucionales; los enfoques o modelos para sus opciones curriculares; los criterios para sus líneas de formación; las competencias genéricas y específicas según sus perfiles de egreso; la convencionalidad de sus ejes, elementos, campos y ámbitos de acción; la significatividad de sus instrumentos didácticos; el impacto de sus productos culturales, entre otros (Aguerrondo, 2005; Trilla, 2007).

En consecuencia, la formación como proceso de humanización reconoce la naturaleza psíquica, comprensiva e interpretativa de los seres humanos. Así como la realidad histórica que posibilita o limita su existencia, sobrevivencia e integralidad. Este itinerario o trayectoria considera el carácter intencional de la conciencia; el dominio inteligible de todo acto de voluntad; y el sentido de trascendencia de las personas. De modo que la constitución, organización, dinámica y transformación del proceso formativo configura la orientación práctica de la autorreflexión de los actores educativos o la búsqueda de sí de los agentes de cambio. Estas experiencias identitarias y operaciones representacionales proyectan el impacto del acto formativo, cuyos cambios psicológicos, pedagógicos y sociológicos de corto, mediano y largo alcance, configuran los fundamentos propios de la personalidad. Lo que supone una cavilación entorno a los significados, valores o verdades asociadas a sus prácticas de enseñanza y procesos de aprendizaje; o una reflexión sobre aquello conocido-aprendido-(re)construido de forma teórico-práctica. Estos aspectos constituyen la identidad formativa, una resignificación del Yo como (re)construcción del acto de enseñar y aprender, lo que implica sistematizar sus saberes, habilidades y actitudes según las modalidades externas, proposiciones de verdad y propiedades inherentes del saber-conocer.

Por último, la dimensión profesional se entiende como la inserción progresiva de los actores sociales a una actividad productiva, un trabajo con derecho a retribución material y simbólica, que exige una formación teórico-práctica sobre los modos de producción. $\mathrm{Al}$ respecto, se entiende que dichos modos conforman las condiciones de existencia de una sociedad y los campos de (im)posiblidades para sus dinámicas culturales, sociales, políticas, económicas, ideológicas, etc. Según el materialismo histórico, la constitución intrínseca y extrínseca de los/las sujetos o las múltiples manifestaciones de su conciencia están condicionadas por las propiedades inherentes del trabajo, cuyas fuerzas productivas y relaciones de producción les permiten hacer frente a sus necesidades, intereses y expectativas, tanto individuales como colectivas (Harnecker, 2007; Abbagnano, 2007).

En tal sentido, las fuerzas productivas describen los ejes, elementos o factores del proceso de producción, es decir, las personas que producen o fuerza laboral; las máquinas, materiales e insumos que emplean para producir o medios de producción; y los conocimientos (inter)disciplinares que les permiten organizar y mejorar el ejercicio teórico-práctico de su trabajo. En cambio, las relaciones de producción establecen los vínculos entre los actores sociales, por lo que regulan la posesión y empleo de los medios de producción; la repartición de los productos generados en el proceso productivo; y la 
expresión jurídica de la propiedad privada. Estas relaciones se mantienen cuando favorecen el desarrollo tecnológico y el potencial de cambio de las fuerzas productivas, o por el contrario, desaparecen si se convierten en un obstáculo de las mismas. Habitualmente, las ideas progresistas se encarnan en una clase social ascendente, que logra imponer sus horizontes de sentido sobre las contradicciones subyacentes y dialécticas entre lo público como fuerza productiva y lo privado como relación de producción (Harnecker, 2007; Abbagnano, 2007).

Las fases de desarrollo de estos modos de producción y distribución de la riqueza configuran los marcos sociales, económicos, políticos, jurídicos e ideológicos de un Estado Nación, ya sea que opte por un sistema de organización (des)centralizado, comunitario, democrático, socialista, socialdemócrata, liberal, capitalista, mercatilista, industrial, etc. Sin embargo, la sociedad fragmentada en clases se asienta en la propiedad privada, esto es, en la lógica de dominio y control de los medios, productos y retribuciones generadas por una actividad económico-productiva. O descansa en la división sexual del trabajo, es decir, en la construcción cultural sobre la diferencia sexual y en las dinámicas socioeconómicas de las relaciones de género. La primera refiere a las cosmovisiones universales y oposiciones binarias atribuidas a los sexos-cuerpos-sexualidades de "sujetos y no sujetos". Esta inteligibilidad cultural o esencialismo genérico, primario, automático e (in)consciente opera mediante esquemas de percepción-apreciación-valoración sobre las semejanzas o diferencias biológico-específicas. Y la segunda define la naturaleza y condición de "los cuerpos que importan y de aquellos que no". Estas dinámicas relacionales configuran los derechos y las obligaciones relativas al trabajo, una normativa político-jurídica y económico-productiva, que establece el (des)prestigio e (in)dependencia entre sus contextos, ámbitos de acción y productos culturales (Amorós, 1991; Montecinos, 1999; Lamas, 1996, 1998; Butler, 2002).

Por consiguiente, las operaciones representacionales asociadas a la división sexual del trabajo y las experiencias identitarias relativas a las relaciones de género, configuran las prácticas discursivas y no discursivas de "sujetos y no sujetos". Estos dispositivos o ejes del poder; epistemes o ejes del saber; y éticas o estados de conciencia de sí y de los/las otros/as, edifican las políticas de la igualdad sobre sus derechos humanos, y las de la diferencia entorno a sus roles y funciones ciudadanas. A partir de los límites, paradojas y disyuntivas entre estos ejes, se advierte que una sociedad asentada en la propiedad privada convierte a la persona en "una mercancía material y simbólica", cuyo capital humano está cosificado o sometido a las leyes del mercado. Estos esquemas de percepción-apreciación-valoración, por una parte (re)producen ciertas jerarquías en todos los niveles de la convivencia social. Y por otra, instalan ciertas subordinaciones y complicidades ante la voluntad dominadora de uno o varios individuos, ante la cual se puede adoptar una condición de sometimiento para aceptarla-justificarla, o una condición de libertad para negarla y salir de ella. (Beauvoir, 1965; Lamas, 2002; Bourdieu, 2000; Steinberg \& Talburt, 2005; Foucault, 2006).

Es así como esta investigación asume una perspectiva de género, ya que pretende poner en discusión los campos de (im)posibilidades, las condiciones de existencia y las dinámicas relacionales entre varones; entre mujeres; entre varones y mujeres. Este enfoque multidimensional se encuentra comprometido con la equidad y justicia social, por lo que reconoce y reivindica los derechos civiles fundamentales de los/las heterosexuales, homosexuales, bisexuales, transexuales, etc. Asimismo, deja de manifiesto las modalidades 
externas, proposiciones de verdad y propiedades inherentes de la ciencia, dado que estas orientaciones epistemológicas, teóricas y metodológicas establecen el carácter asexuado, objetivo y neutral de su objeto de estudio. Como también, desmitifica los modos de (re) producción, distribución y aplicación del conocimiento, puesto que la imparcialidad e impersonalidad de sus saberes, habilidades y actitudes oculta las condiciones de clase, etnia y género de sus actores protagónicos (Montecinos, 1999; Butler, 2006; Irigaray, 2007; Lizana, 2009).

Al respecto, se propone analizar los intereses, necesidades y expectativas de las comunidades científicas y/o equipos de investigadores/as, de manera que sus expresiones lingüísticas y acciones comunicativas incluyan las alternativas de la diferencia y los condicionamientos de la alteridad. Esto quiere decir que un objeto, problema, hecho y/o fenómeno es distinto o diferente, sólo en cuanto tienen en común aquello en que difieren. Al punto que la otredad como cosa nombrada pueda ser la negación de sí misma, o la idea sobre la forma del/la otro/a se constituya según la exterioridad de sus aspectos comunes, propios y/o accidentales. En sentido explícito e implícito, las propiedades específicas establecen una diferencia constitutiva respecto de su especie, y las generales conforman una diferencia divisiva con referencia a su género. De esta manera, es conveniente revisar el carácter conceptual, procedimental y actitudinal de estos enunciados, ya que sus nociones sirven como reglas para comprender las formas de ser y estar en el mundo; sus distinciones se utilizan como actividades para investigar un contexto local y específico; y sus categorías se disponen como criterios de validez o condiciones para formalizar-legitimar la experiencia de conocer-aprehender-(re)construir de los/las sujetos de estudio. En consecuencia, el conocimiento científico configura una relación entre las palabras y las cosas, donde las funciones lógicas del Yo, Yo-Tú, Yo-Otro/a, Yo-Nosotros/as, Nosotros-Nosotros/as están revestidas por la matriz significativa de su contexto histórico y por las formas de pensamiento de su realidad sociocultural.

Por tales razones, la pregunta de investigación: cuáles son las prácticas discursivas y no discursivas de los/las sujetos de estudio, procura darle mayor vitalidad, diversificación y complejidad al plano teórico-práctico de esta actividad indagativa. Lo que implica comprender cómo se (re)construye la igualdad-diferencia sexual en un contexto local y específico; cómo se constituye la paridad-diversidad entre los sexos según sus campos de (im)posibilidades y condiciones de existencia; cómo se configura la homogeneidad-heterogeneidad en la dimensión personal, social, formativa y profesional de sus áreas (inter)disciplinares; cómo se (des)articula el imperativo heterosexual y la norma patriarcal con los roles y funciones atribuidas a estos actores sociales; cómo se expresa la voluntad de dominio en sus modos de saber-ser, saber-convivir, saber-conocer y saber-hacer; cómo se manifiesta la subordinación y complicidad en el juego de relaciones, individuales y colectivas; etc.

Si bien, las estructuras, dinámicas y factores socioeconómicos, políticos, jurídicos e ideológicos condicionan el devenir histórico o mantienen un peso relativo en la configuración del contexto local y específico de los/las sujetos. Estas formas de vida no determinan sus potencialidades innatas y actos de conciencia, ni prescriben los procesos de (re)construcción de sí mismo/a, frente al imperativo categórico que estipulan estas normativas individuales y colectivas. Por ello, se entiende que los grados de libertad, independencia y protagonismo de los actores sociales constituyen la historicidad de la praxis humana, es decir, una red (dis)continua y compleja de (re)acciones, que procura perfeccionar las condiciones materiales y simbólicas de existencia. 
Por consiguiente, la dimensión profesional describe la inserción, intervención y transformación progresiva de los actores sociales en fuerza productiva, lo que exige una formación teórico-práctica sobre las relaciones de producción. A fin de que estos saberes, habilidades y actitudes representen una circularidad dialéctica entre pensamiento y acción, donde la dinámica o sinergia del vínculo teoría-práctica anule la primacía de una sobre otra. Al respecto, Dewey (2008) resalta el carácter instrumental de las perspectivas teóricas, destacando como etapas fundamentales la (auto)acción, interacción y transacción en el proceso de conocer-aprehender-(re)construir o en la relación de conocimiento entre un sujeto de estudio y un objeto cognoscente. Por ello, propone el diseño, implementación y evaluación de proyectos de investigación, de manera que los actores educativos se sumerjan en las complejidades e implicancias de la experiencia-práctica, a partir de la reflexión de sus necesidades, intereses y expectativas. Un saber-hacer, que se constituye en instancia formativa, significativa y operativa cuando está comprometido con el cambio y la mejora del ambiente natural y social.

Del mismo modo, Giroux (2006) reivindica el carácter autónomo, político y crítico de la actividad intelectual, entendiendo que estos horizontes de sentido surgen en un contexto local y específico; y sus significados, valores o verdades refieren a una (re) acción real y concreta. En tal sentido, la autonomía de la teoría confiere eficacia a la práctica cuando sus fuerzas o energías transforman lo existente, entendiendo que la relación de conocimiento está condicionada por los grados de (dis)continuidad, distinción y complementariedad de una con respecto a la otra. Estas ideas resaltan el perfil histórico y lingüístico del pensamiento y de las experiencias de los actores sociales, los que (re) producen, distribuyen y aplican sus saberes, habilidades y actitudes según las condiciones materiales y simbólicas de la práctica como praxis. Al respecto, se concibe que la teoría es en sí misma un acto de conocimiento porque reúne la totalidad de (re)acciones, expresiones, comportamientos y autorregulaciones humanas, conformando los modos del Yo, del Yo-Tú, del Yo-Otro/a, del Yo-Nosotros/as, del Nosotros/as-Nosotros/as. Esta dimensión objetiva, subjetiva e intersubjetiva supone la existencia de una (re)construcción conjunta sobre los horizontes de sentido de lo propio, lo común y la otredad. Como también, implica un acto performativo, cognoscitivo, emocional, lingüístico e interactivo, en tanto, los/las sujetos comprenden sus formas de ser y estar en el mundo de la vida.

De esta manera, la mediación dialéctica entre teoría-práctica tiene un interés crítico y emancipador orientado a la superación de las relaciones de poder, cuyas coacciones externas e internas se encuentran invisibilizadas y naturalizadas en los procesos de (re) producción, distribución y aplicación del conocimiento. Por lo que se trata de develar cuáles son los intereses explícitos e implícitos de estas formas de conocimiento; cómo sus categorías de análisis, medios de socialización y campos de (im)posibilidades configuran los modos de saber-ser, saber-conocer, saber-hacer y saber-convivir de los/las sujetos; y cómo esta estructuración psíquica, comprensiva e interactiva potencia u obstaculiza su disposición crítica y reflexiva ante los mismos. Estas condiciones de existencia conforman la identidad profesional de los actores sociales, una resignificación del Yo como praxis de una actividad teórico-práctica, lo que implica su (re)estructuración progresiva e (inter) disciplinaria según las modalidades externas, proposiciones de verdad y propiedades inherentes del saber-hacer (Giroux, 2006).

En consecuencia, esta investigación pretende analizar la dimensión personal, social, formativa y profesional de la Formación Docente Inicial. Una preparación pedagógica e 
(inter)disciplinaria destinada para el profesorado o para aquellas personas adultas que han elegido ejercer un conjunto de roles y funciones en el Sistema Nacional de Educación. En sentido amplio, la formación comprende el acto de aprender, esto es, los fundamentos, propósitos, modalidades y resultados de los procesos de aprendizaje. Como también, el acto de enseñar, es decir, los principios, finalidades, circunstancias y productos de las prácticas de enseñanza. Estos actos educativos se encuentran asentados en un sistema de organización sociocultural, cuyas condiciones materiales y simbólicas (re)producen, distribuyen y aplican una serie de saberes, habilidades y actitudes según sus distintos niveles de complejidad (Stenhouse, 1998; Pozo \& Scheuer, 2006).

Consiguientemente, este estudio pretende analizar las dimensiones de la Formación Docente Inicial, a partir de las prácticas discursivas y no discursivas de sus actores protagónicos. Para ello, la investigadora les presenta estos ejes, elementos y procesos de modo (in)dependiente, emergente, contingente y (de)constructivo, a fin de que los/las sujetos de estudio visibilicen sus puntos de (des)articulación, esferas temáticas y nudos problemáticos. O adviertan cuál(es) es(son) la(s) perspectiva(s) epistemológica(s), teórica(s) y metodológica(s) que subyace(n) en cada dimensión; cómo las expresiones lingüísticas y acciones comunicativas configuran estos modos de saber-ser, saber-convivir, saberconocer y saber-hacer; cómo las formas de (re)construcción, distribución y aplicación del conocimiento pedagógico e (inter)disciplinar están asociadas-integradas-incluidas o disociadas-fragmentadas-desmembradas, de los procesos de subjetivación, objetivación e intersubjetivación; cómo se expresan y comunican las operaciones representacionales asociadas a la división sexual del trabajo y las experiencias identitarias relativas a las relaciones de género, etc.

Por tales razones, esta investigación asume el construccionismo epistemológico como horizonte de sentido, puesto que procura comprender la complejidad, recursividad, (dis) continuidad e (in)estabilidad de estos contextos y procesos formativos. Así como atender a las diferencias históricas, culturales, sociales, económicas, políticas e ideológicas entre los/las sujetos de estudios. Al respecto, se entiende que estos (des)acuerdos pueden encontrarse en los tipos de saberes, habilidades y actitudes adoptados en su realidad local y específico; en las modalidades convencionales e informales de sus modalidades de lenguaje; o se expresan de manera (in)conciente, (in)visibilizada, dispersa, anónima y/o naturalizada, en las pautas conceptuales, procedimentales y actitudinales dispuestas para sus formas de organizar y estructurar el conocimiento. Estas diferencias sustantivas y significativas tienen un carácter histórico, contingente y semiológico, dado que la relación palabra-cosa permanece durante un periodo de tiempo o responde a las necesidades, intereses y expectativas de una época determinada. Esto quiere decir que una expresión lingüística y acción comunicativa evidencia cambios radicales, imprecisos e inexplicables, cuando sus condiciones de existencia y campos de (im)posibilidades no pueden describir, interpretar o analizar del mismo modo, un objeto, problema, hecho y/o fenómeno sociocultural.

Por su parte, las perspectivas teóricas de esta investigación procuran vislumbrar el contexto sociocultural, premisas intelectuales y lógicas de acción, que subyacen a los modos de producción (fuerza productiva y relación de producción) de la Formación Docente Inicial. Como también, atender a los enfoques, fundamentos y métodos (estrategias, técnicas e instrumentos) seleccionados, implementados y validados por su comunidad científica o equipo de investigadores/as. Entonces, la (re)construcción teórico-práctica refiere a la 
comprensión teleológica de estos procedimientos, puesto que le atribuye un origen material, estructura formal, propósito determinado y utilidad concreta, a su objeto de estudio y unidades de análisis. Esta orientación filosófica, filológica y axiológica evidencia el cuerpo pedagógico e (inter)disciplinario coexistente en sus manifestaciones discursivas, aplicaciones metodológicas y técnicas productivas. Por lo que condiciona el carácter hipotético, interpretativo, relativo e imperfecto de sus observaciones, utilizándolas como instrumento de investigación sobre un hecho y/o fenómeno educativo. O como mecanismo de verificación, validación o corroboración entorno a los axiomas y demostraciones del mismo (Taylor \& Bogdan, 1986; Flick, 2004; Abbagnano, 2007).

Este conjunto de proposiciones, criterios o parámetros puede ser aceptado tal como se manifiesta en los textos orales y escritos de la Formación Docente Inicial, o se admite de manera (in)conciente, sin necesidad de demostrar sus repercusiones materiales y simbólicas. Ya sean divergentes o convergentes las perspectivas teórico-prácticas adoptadas para sus contextos y procesos formativos, estas posturas han sido ajustadas al campo de experiencias que se desea describir, interpretar y analizar. A su vez, éste ha puesto en crisis los sistemas de clasificación y los criterios de validez de sus áreas primigenias y auxiliares, por las siguientes razones (Bisquerra, 2004; Pozo \& Scheuer, 2006):

a) La Formación Docente Inicial constituye un cuerpo pedagógico e (inter)disciplinario, de modo que el esqueleto teórico-práctico de sus dimensiones procura unificar conocimientos de naturaleza distinta. Los puntos de (des)articulación, esferas temáticas y nudos problemáticos entre estos saberes, habilidades y actitudes constituyen un horizonte de sentido, un elemento de juicio para la confiabilidad y validez de sus significados, valores o verdades.

b) La Formación Docente Inicial configura las operaciones representacionales asociadas a la división sexual del trabajo y las experiencias identitarias relativas a las relaciones de género. Estos procesos de subjetivación, objetivación e intersubjetivación se estructuran psíquica, comprensiva e interactivamente por medio de ciertas condiciones históricas, sociales, económicas, políticas, ideológicas, etc. Un campo de (im)posibilidades, cuyas experiencias reales y concretas conforman los principios, finalidades, modalidades y productos de esta formación. Así como, distinguen los espacios, ámbitos de acción y productos culturales de sus actores protagónicos.

c) La Formación Docente Inicial conforma un conjunto de reglas de inferencia, el que permite establecer la relación entre dos proposiciones lógicas y la ilación de los antecedentes, consecuencias e implicancias de un hecho y/o fenómeno educativo. Este proceso complejo, (dis)continuo e (in)formal genera una red de deducciones e inducciones, un tejido de conjeturas, conclusiones y contradicciones, que supone la previsión de una determinada información o de ciertos datos extraídos de un contexto socioeducativo.

d) La Formación Docente Inicial genera una matriz significativa para la experiencia de conocer-aprehender-(re)construir un objeto de estudio. Estas explicaciones hipotéticodeductivas o comprensiones analítico-sintéticas procuran establecer el carácter parcial o global de sus unidades de análisis.

En tal sentido, esta investigación asume como perspectiva teórico-práctica el interpretativismo, ya que procura vislumbrar la complexión de las interacciones humanas; el perfil historiográfico de los actores sociales; y el carácter teleológico de aquellos significados, valores o verdades configurados mediante el lenguaje. Al respecto, se entiende que estos atributos se hallan parcialmente constituidos por los enunciados empleados para 
describirlos, interpretarlos y analizarlos. De modo que su matriz significativa depende del entorno histórico, cultural, social, político, económico, ideológico y lingüístico, donde éstos emergen. Así como descansa en las intenciones, intereses y compromisos de las personas que los (re)significan. En otras palabras, el escenario de estudio constituye un eje articulador de las expresiones lingüísticas y acciones comunicativas del actor situado, cuya actuación-enunciación performativa puede ser comprendida, en virtud, de la inteligibilidad cultural de sus prácticas discursivas y no discursivas (Sandín, 2003; Castro, 2004; Foucault, 2006).

Habitualmente, estas formulaciones teórico-prácticas adoptas múltiples formas lingüísticas. Se trate de un lenguaje caracterizado por constantes lógico-matemáticas de tipo extensivo e intencional, a fin de establecer ciertas conexiones enunciativas entre parámetros, medidas y cuantificadores. O puede instaurar ciertas regularidades discursivas a partir de la clasificación, magnitud, longitud, volumen, tamaño, etc., de uno o varios objetos cognoscentes. O puede utilizar términos genéricos, distintivos e inclusivos para (in)visibilizar la diferencia-alteridad y/o igualdad-paridad entre los/las sujetos, cuya inteligibilidad cultural establece entidades, propiedades y relaciones, abstractas e (im) perceptibles. Esta estructura sociolingüística configura los axiomas teórico-prácticos de un campo de estudio, una red de distinciones explícitas e implícitas, que (des)articula las reglas de formación, dinámica y transformación de sus enunciados (Daniel, 2002; Iñiguez, 2006).

Según tales premisas, esta investigación entiende que la dimensión personal, social, formativa y profesional de la Formación Docente Inicial configura un campo de estudio. Una red de distinciones epistemológicas, teóricas y metodológicas, que (des)articula los conocimientos pedagógicos con los (inter)disciplinares; los hechos y/o fenómenos educativos con la contingencia de su realidad sociocultural; los modos de saber-ser, saber-convivir, saber-conocer y saber-hacer con sus experiencias locales y específicas, entre otras. Si bien, la matriz significativa de estos contextos y procesos formativos se manifiesta como tal, la (re)interpretación o (re)significación de los significados-significantes está condicionada por los horizontes de sentido del observador/a, y por los enfoques reticulares de sus formulaciones lingüísticas. De modo que estas prácticas discursivas y no discursivas asumen el nivel fonológico, semántico, morfológico, sintáctico y pragmático, tanto de los modelos extendidos por su comunidad científica o equipo de investigadores/as, como por las entidades, propiedades y relaciones (re)construidas por sus actores protagónicos. Por lo tanto, una reflexión teórico-práctica sobre cada dimensión supone comprender cómo se organiza axiomáticamente en el sistema de enunciados y en el conjunto de reglas, de dicha formación; o cómo se estructura axiológicamente en la experiencia de conoceraprehender-(re)construir. (Molina, 2001, 2005; Lizana, 2007, 2008, 2009)

Además, este estudio concibe que la (re)producción, distribución y aplicación del conocimiento equivale a especificar cómo las estructuras socioculturales y las relaciones de poder condicionan el abordaje de un objeto cognoscente, un problema de investigación, un hecho y/o fenómeno observable; cómo la indagación científica comprende los modos de producción y los campos de fuerza, que repercuten en sus valoraciones políticas, económicas, ideológicas y lingüísticas; cómo la experiencia de conocer-aprehender-(re) construir "se hace cargo" de las actuales temáticas y problemáticas sobre clase, género y etnia. Al punto que el acto de comprender involucre una acción práctica emancipadora, en tanto, se pregunte: por qué la actividad científica o investigativa tiende a la conservación, 
simplicidad, compatibilidad, equilibrio y/o coherencia de sus lógicas de funcionamiento; por qué éstas se distancian de las experiencias periféricas, alternativas y nómades de la nueva generación de ciudadanos/as, y de sus propósitos de libertad, democracia y justicia social. De manera tal que el acto de investigar adopte una visión horizontal y equitativa del conocimiento, en virtud, de un encuentro dialógico entre investigadores/as y participantes. Para así poner en común la conciencia de sí y la del/la otro/a como "un/a legítimo/a otro/a en la convivencia", sobre el valor pragmático, relativo y contextual de las contradicciones existentes.

Esta reflexión teórico-práctica se genera mediante los usos del lenguaje, cuya estructura y organización sociolingüística, funciones discursivas y combinaciones de signos permiten la comunicación entre las personas. Ya se entienda una lengua como producto arbitrario de las convenciones sociales o un lenguaje como facultad multiforme y heteróclita de dominio individual o colectivo, el sistema de reglas de su matriz significativa condiciona la relación entre las palabras y las cosas. O dicho de otro modo, estas conexiones morfosintácticas regulan el funcionamiento de los signos lingüísticos, y los (des)articulan con sus objetos materiales y simbólicos, y con los estados de subjetivación, objetivación e intersubjetivación, que de ellos se desprenden. $\mathrm{Al}$ respecto, se entiende que las condiciones de existencia y campos de (im)posibilidades de las funciones del discurso están mediatizadas por el desarrollo filogenético y ontogenético de la especie. Y que la formación, dinámica y transformación de sus significados, valores o verdades están permeadas por las operaciones, actuaciones o elecciones performativas, de los actores sociales (Daniel, 2002; Iñiguez, 2006).

En efecto, el discurso se concibe como un cuerpo de premisas, enunciados, normas, conexiones e inferencias, relativamente organizado y distintivo. Sin embargo, sus modelos explicativos y unidades de sentido adoptan un carácter heterogéneo, cambiante e imprevisible, dado que oscilan según la finalidad pragmática de quienes se comunican. Esto quiere decir que el dialogo como ejercicio de entender(se) dentro de una comunidad lingüística pone de manifiesto la eficacia e intención comunicativa del Yo, Yo-Tú, YoOtro/a, Yo-Nosotros/as, Nosotros/as-Nosotros/as. Por lo que evidencia las condiciones de existencia y las nociones de verdad de sus prácticas discursivas y no discursivas; y las exigencias axiomáticas y praxiológicas sobre sus modos de saber-ser, saber-convivir, saber-conocer y saber-hacer. A partir de este contexto de conversación, se puede comprender los principios de cooperación y conflictos de intereses de las interacciones humanas; las temáticas y problemáticas de la enunciación; y los efectos intencionales de los actos lingüísticos (Daniel, 2002; Iñiguez, 2006).

Por ello, esta investigación entiende que las interjecciones, onomatopeyas e inflexiones de la voz; las expresiones verbales y no verbales; las locuciones corporales o gestuales; las entonaciones emocionales y afectivas; los términos ambiguos, erróneos o verdaderos; los mitos, cantos y leyendas; los murmullos, cavilaciones y silencios; las metáforas; los conceptos; las proposiciones narrativas, poéticas o dramáticas; entre otros, son unidades fundamentales de la comunicación. Si bien las personas contribuyen de manera informativa, pertinente y adecuada en la conversación o en la interacción cara a cara, sus modelos de objetividad, subjetividad e intersubjetividad van más allá del significado literal de aquello que se desea manifestar. En otras palabras, cuando se comunica algo a alguien en un contexto local y específico, estas unidades de sentido generalmente exceden, divergen o contradicen las condiciones de existencia y las nociones de verdad de 
las palabras empleadas o de las cosas nombradas. Por lo tanto, los niveles de implicación en el dialogo configuran las cosmovisiones u horizontes de sentido sobre un objeto de estudio; distinguen la existencia psíquica, abstracta, relacional, inmediata u observable de sus unidades de análisis; y describen su particularidad y variabilidad en un momento, lugar o contexto determinado. Esta gramaticalidad (con)textual o referencial constituye el sistema de enunciados y el conjunto de reglas para sus presuposiciones existenciales, usos cotidianos, expresiones lingüísticas y acciones comunicativas (Wodak \& Meyer, 2003; Calsamiglia \& Tusón, 2008).

Efectivamente, la gramática del texto describe las modalidades externas, proposiciones de verdad y propiedades inherentes de las prácticas discursivas y no discursivas de los/las sujetos. De modo que la (re)construcción del significado no sólo depende de la estructura morfonsintáctica de los enunciados, sino de la referencia oportuna de sus indicadores y de la finalidad pragmática en la que estos son empleados. Este contexto de enunciación procura atender a las propiedades específicas, extensivas e intencionales de las palabras, por lo que sus significados, valores o verdades son el resultado de una connotación o de una significatividad por asociación entre las mismas. Asimismo, estos horizontes de sentido evidencian la realidad sociolingüística de una comunidad, puesto que le asigna una denotación a la sustancia simbólica de las palabras y a la sustancia material de las cosas, dentro de sus condiciones de existencia y campos de (im)posibilidades. Una relación abstracta y figurativa, que denota las formas lógicas, funciones semióticas y fuerzas ilocutorias de lo expresado en su contexto habitual (Wodak \& Meyer, 2003; Calsamiglia \& Tusón, 2008).

En consecuencia, esta investigación concibe a la gramática como un sistema de enunciados o como un dominio-método de análisis de las proposiciones dichas y escritas, por lo que considera la dispersión de sus acontecimientos socioculturales, y la singularidad de sus expresiones lingüísticas y acciones comunicativas. Al respecto, Foucault (2006) señala que la descripción arqueológica examina el sistema de clasificación, coordinación y subordinación de los enunciados, e indaga en las condiciones de existencia de tales proposiciones, puesto que este conjunto de reglas establece la formación, dinámica y transformación para sus unidades lógicas. Asimismo, especifica que la performance verbal o modalidad de (re)producción lingüística establece una relación sistemática entre los signos adoptados por una lengua natural o artificial. Como también, manifiesta que la formulación es el acto individual o colectivo, donde surge la función enunciativa del hablante; la estructura proposicional del referente-significante; y la composición material y simbólica del signo, en virtud, de su correlato de sentidos y significados en una frase. Si bien, el trabajo arqueológico instaura una distinción entre las condiciones de existencia de las formaciones discursivas y los campos de (im)posibilidades de los enunciados, el dominio-método asociado a sus unidades de análisis instala una correlación entre el orden lógico-retórico del sujeto-objeto de la (re)interpretación, y el orden lógico-sintáctico del sujeto-objeto de la formalización.

Gracias a estos elementos y sus combinaciones, los actores sociales pueden configurar los principios generales y específicos de un fenómeno lingüístico o pueden enfrentar situaciones discursivas peculiares, (in)usuales o (des)conocidas. De manera que el uso efectivo y creativo del lenguaje dentro de un orden existente de cosas, refleja las competencias lingüísticas y comunicativas de quienes se comunican consigo mismo o con los demás. Estos saberes, habilidades y actitudes les permiten comprender que la relación entre las 
palabras y las cosas no es una simple equivalencia, sino una articulación compleja de inferencias proposicionales. Es así como las competencias evidencian un proceso dinámico y (dis)continuo de (re)significaciones, una semiosis entre tres entidad irreductibles: enunciado - objeto cognoscente - interpretador/a. De modo que el primero refiere a una convención arbitraria sobre la existencia material o simbólica del segundo; este constituye el medio por el cual se perciben los signos del primero; y el tercero interpreta este juego de relaciones mediante su matriz significativa (Daniel, 2002; Iñiguez, 2006; Wodak \& Meyer, 2003; Calsamiglia \& Tusón, 2008).

Por ello, esta investigación se pregunta por las categorías contextuales e (inter) disciplinarias de la Formación Docente Inicial, y por el carácter funcional e inferencial de sus expresiones lingüística y acciones comunicativas. Estas prácticas discursivas y no discursivas conforman una trama semántica, es decir, un conjunto de relaciones de los signos con los objetos a los que se refieren; una trama sintáctica, esto es, un conjunto de relaciones (in)formales de los signos entre sí; y una trama pragmática, es decir, un conjunto de relaciones de los signos con sus actores protagónicos. Al respecto, se concibe que las experiencias personales, sociales, formativas y profesionales configuran la matriz significativa de toda interpretación o de toda posibilidad de referencia, de manera que estos significados, valores o verdades, extensionales e intencionales, residen en los usos empleados para saber-ser, saber-convivir, saber-conocer y saber-hacer.

A partir de esta reflexión se puede comprender por qué los/las sujetos de estudio utilizan múltiples y disímiles horizontes de sentido para referirse a un mismo objeto, cosa, problema, hecho y/o fenómeno de la realidad. Este aspecto considera las competencias lingüísticas y comunicativas del actor situado, cuyas formas de entendimiento le permite socializarlos como circunstancias o acontecimientos habituales, extraños, insólitos, problemáticos o novedosos. En tal sentido, la descripción, interpretación y análisis de los contextos formativos, procura visibilizar aquellas relaciones explícitas e implícitas entre sus epistemes o modos de saber, así como aquellos referentes-significantes (in)concientes que ocupan el lugar de alguna cosa. A modo de distinguir, la significación atribuida por el arbitrio de las convenciones sociales, o por la suposición conferida a la estructura proposicional de los términos empleados. Asimismo, este procedimiento intenta develar las modalidades externas, proposiciones de verdad y propiedades inherentes de los procesos formativos, donde la dimensión personal, social, formativa y profesional puede adoptar un carácter demostrativo porque indica una designación presente; un carácter proyectivo puesto que indica una designación futura; un carácter rememorativo, dado que indica una designación pasada; o un carácter sensible, ya que designa un estado emocional (Lizana, 2007, 2008, 2009).

Por lo tanto, la experiencia de conocer-aprehender-(re)construir las prácticas discursivas y no discursivas de los actores protagónicos de la Formación Docente Inicial, procura describirlas, interpretarlas y analizarlas según su articulación pragmática y composición semántica. Entendiendo que la reactivación crítica del juego de relaciones entre los/las sujetos de estudio y sus objetos cognoscentes considera las formas gramaticales y usos (con)textuales de sus enunciados. En virtud de comprender que la significación como imposición arbitraria del significado y extensión del sentido connota los campos de (im) posibilidades de la referencia-mediata y las condiciones de existencia de los términos aplicados a las cosas reales. Mientras que la suposición como aceptación social del significado y comprensión del sentido denota los campos de (im)posibilidades de la referencia-relativa y las condiciones de existencia de los términos aplicados a las cosas posibles. 
La configuración de estos significados y sentidos describe un conjunto de proposiciones complejas y (dis)continuas, de manera que el actor situado en una praxis interactiva (re)construye una inferencia interpretativa sobre lo que significa y lo que es la cosa indicada, según adopte una postura amplia o restringida. En tal sentido, la formación, dinámica y transformación de toda posibilidad de referencia está definida por el uso de las palabras en una comunidad lingüística. Donde la connotación y denotación de los términos empleados en una situación comunicativa, expresa la cualidad disposicional, sensible o emocional de las entidades percibidas, por lo que provoca estados, sensaciones o reacciones afectivas entre quienes interactúan. Así como, evidencia la cualidad intencional, deliberada o premeditada de las entidades declaradas, la que conforma el valor funcional y operativo de las lógicas de acción dentro de las dimensiones propias de una matriz significativa. Finalmente, manifiesta la cualidad figurativa, intuitiva o creativa de las entidades polivalentes, por lo que evoca una asociación libre de pensamientos o una proyección de imágenes mentales sobre algo intangible, espiritual, sagrado e imaginado (Wodak \& Meyer, 2003; Calsamiglia \& Tusón, 2008; Kabatek, 2008).

Consiguientemente, una entidad percibida, declara o polivalente puede expresar una operación cualquiera, un estado de actividad o pasividad, una práctica cognoscitiva o sociolingüística, un fin al que se tiende, una cosa deseada, una cualidad o realidad observada, una imagen de la fantasía, un concepto pensado, entre otras. Entonces, las entidades conocidas-aprendidas-(re)construidas tienen como término un objeto de saber y como límite un ámbito de acción. La (re)interpretación o (re)significación de estos esquemas, operaciones y resultados permiten reconocer el carácter material, cognoscitivo, intencional, abstracto y/o intangible de un objeto de estudio, cuyos sentidos y significados son atribuidos a su propio acto de conciencia. Según Dewey (2008) las cosas observadas o pensadas están (re)producidas, distribuidas y aplicadas sistemáticamente por medio de la investigación, por lo que su objeto, problema, hecho y/o fenómeno describe los horizontes de sentido de dicha actividad indagativa.

O dicho de otro modo, las cosas manifestadas como tal, es decir, los cuerpos físicos o materiales; las entidades simbólicas, abstractas o (i)lógicas; los valores o verdades; los estados psíquicos o emocionales, etc., se hallan provistos de un carácter peculiar y de una validez particular, según la connotación y denotación de sus significados restringidos o específicos. En consecuencia, esta investigación concibe al objeto de estudio como el resultado de una operación de búsqueda y pesquisa, una indagación que procura describir, interpretar y analizar cuál es su contexto de enunciación; cuáles son sus circunstancias históricas y contingencias socioculturales; cuáles son sus componentes estructurales y relaciones constituyentes; quiénes son sus actores protagónicos; cuáles son las condiciones de verdad para su inferencia interpretativa; cómo se utilizan, verifican o aseveran sus expresiones lingüísticas y acciones comunicativas; cuáles son los procesos de subjetivación, objetivación e intersubjetivación asociados a estas prácticas discursivas, etc. Se trata de comprender cómo el valor simbólico de todo enunciado connota una significación, y cómo el carácter recíproco de todo dialogo denota una suposición, sobre una interpretación posible de los significados y sentidos coexistentes en una expresión o acción. En esta praxis interactiva converge una coordinación de coordinaciones de mensajes múltiples, los que permiten socializar los principios y mecanismos de la comunicación intersubjetiva, y la alteridad de sus enunciados comprensivos e interpretativos. Inclusive, estos principios se aplican para aquellas inferencias o proposiciones aparentemente sin 
sentido, absurdas, ilógicas, paradójicas y contradictorias, ya que podrían connotar o denotar otros nexos conceptuales, procedimentales y actitudes, no (re)significados con anterioridad (Dewey, 2008) .

Asimismo, esta investigación asume como perspectiva metodológica el enfoque cualitativo. Una actividad sistemática, compleja e (inter)disciplinaria, que está orientada a la comprensión profunda de un objeto de estudio. Desde este punto de vista, se entiende que las prácticas discursivas y no discursivas de los actores protagónicos de la Formación Docente Inicial, constantemente conocen-aprehenden-(re)construyen los significados, valores o verdades asociadas a su dimensión personal, social, formativa y profesional. Una configuración de la Identidad Profesional Docente desde una perspectiva de género, que por una parte (re)significa los modos de saber-ser, saber-convivir, saber-conocer, y saber-hacer de los/las sujetos de estudio, a la luz de sus experiencias objetivas, subjetivas e intersubjetivas. Y por otra, moviliza las operaciones representacionales asociadas a la división sexual del trabajo, y las experiencias identitarias relativas a las relaciones de género, según las estructuras de su pensamiento y los usos convencionales de su lenguaje. Por tales razones, dicha actividad indagativa procura conformar un cuerpo organizado de saberes, habilidades y actitudes sobre estos contextos y procesos formativos, de modo que la adopción de ciertas formas de (re)producción, distribución y aplicación del conocimiento sea atingente a su campo de estudio y unidades de análisis. En tal sentido, se intenta implementar un conjunto de acciones descriptivas, interpretativas y analíticas, a fin de comprender las disposiciones emocionales, intenciones premeditadas, intuiciones creativas y condiciones de verdad de los enunciados o proposiciones empleadas por esta comunidad lingüística (Pérez, 1998; Sandín, 2003; Bisquerra, 2004).

$\mathrm{Al}$ respecto, se concibe que una de las características fundamentales de la investigación cualitativa es su atención al contexto histórico, cultural, social, económico, político, ideológico y lingüístico de los/las sujetos de estudio, ya que esta connota el significado de sus expresiones lingüísticas y denota el sentido de sus acciones comunicativas. De una u otra forma, el entorno local y específico condiciona la movilidad espacio-temporal de las experiencias humanas, y perfila el ambiente sociolingüístico de sus actores protagónicos. Según modos y grados diferentes, la investigadora procura comprender el conjunto de supuestos coexiste en el escenario de estudio, a fin de que su mirada holística o global, le permita conocer-aprehender-(re)construir el significado parcial y sentido íntegro de los enunciados empleados. Por ello, la responsable de este estudio reflexiona sobre sí misma y mantiene una vigilancia epistemológica en el transcurso de la conversación con los/ las participantes, entendiendo que estos grados de conciencia o formas particulares de pensar(se), entender(se) e interrogar(se) repercuten en la estructuración psíquica, comprensiva e interactiva de cada acontecer (Sandín, 2003; Flick, 2004).

En esta relación de conocimiento, el principio de razonamiento describe el YoInvestigadora como instrumento, por lo que examina sus modelos, criterios y actos de voluntad, o se repliega en torno a sus operaciones representacionales y experiencias identitarias sobre la conciencia de sí y la del otro/a. De esta manera, la reflexión como abstracción visibiliza los límites o restricciones de la experiencia de conocer-aprehender(re)construir, ya que sus actos (in)voluntarios y productos generados abstrae, separa o aísla los procesos de objetivación, subjetivación e intersubjetivación de la investigadora, de las condiciones materiales y simbólicas de la cosa manifestada como tal. Por consiguiente, la abstracción es inherente a cualquier actividad indagativa, cuyas lógicas de acción, 
operaciones selectivas y recursos lingüísticos configuran el carácter distintivo y la forma proposicional de su objeto de estudio (Sandín, 2003; Hernández, Fernández, Baptista, 2006).

Asimismo, los principios de calidad, equidad y reciprocidad son cruciales para este estudio cualitativo, por ello, la interacción entre la investigadora y los/las participantes intenta configurar una comunidad dialógica, flexible, respetuosa y dinámica. Una coordinación de acciones, reacciones y afecciones mutuas, a fin de que las personas involucradas (re)conozcan-aprehendan-(re)construyan sus horizontes de sentido sobre esta relación de conocimiento. Al respecto, se concibe que las perspectivas epistemológicas, teóricas y metodológicas circunscriben el conjunto de intenciones de los/las observadores/as y el dominio de lo posible de su praxis indagativa. Una experiencia libre, voluntaria y responsable orientada a develar, tanto el carácter inmanente, contingente y (dis)continúo de sus pretensiones de verdad, como el ámbito sociopolítico de sus producciones conceptuales, procedimentales y actitudinales. La comprensión de estos modos inferenciales o proposicionales es necesaria, puesto que explícita o implícitamente conforman las condiciones de existencia y los campos de (im)posibilidades del acto de conocer, cuya modalidad investigativa puede (in)visibilizar las semejanzas o diferencias, que se advierten ante la producción de sí (Eisner, 1998; Abbagnano, 2007).

Igualmente, lo cualitativo se identifica por sus operaciones descriptivas, interpretativas y analíticas ante el material de investigación. Actividades caracterizadas por una cierta finalidad e implementadas según reglas determinadas, que por una parte dan validez al principio que enuncia y por otra singularizan la cosa nombrada, confrontándola o diferenciándola de otras. Es así como la descripción muestra con total transparencia las expresiones lingüísticas y acciones comunicativas de la investigadora y las de los/ las participantes, ya que las propiedades habituales, espontáneas y accidentales de estos enunciados connotan su significado y denotan su sentido, dentro de un contexto local y específico. Estas operaciones descriptivas procuran recuperar la voz y el protagonismo de los actores sociales, puesto que sus formas de pensamiento y modalidades narrativas admiten tácitamente el valor de verdad de un objeto de estudio. Por consiguiente, esta caracterización intenta develar la intención referencial y posición existencial de quienes hablan. A fin de considerar tanto las atribuciones reflexivas y comprensivas que delinean el campo de acción de sus palabras, como las impresiones contextuales y extensivas que subyacen en su entorno mediato-real o relativo-posible (Daniel, 2002; Iñiguez, 2006).

Asimismo, la interpretación como operación metodológica considera el carácter directivo de toda exégesis o elucidación. Por lo que procura esclarecer la orientación ideológica de los/las sujetos de estudio, o explicitar aquellos significados y sentidos coexistentes en sus prácticas discursivas y no discursivas. En tal sentido, lo ideológico muestra la dependencia entre el conjunto de creencias filosóficas, religiosas, políticas, morales, etc., de un grupo humano y los intereses socioeconómicos de las relaciones de producción. Esta visión de mundo o cosmovisión caracteriza las ideas sobre la fuerza productiva, por lo que trasciende "toda situación de facto", en virtud, de persuadir, dirigir o tutelar los proyectos y lógicas de acción de los actores sociales. De este modo, las orientaciones ideológicas controlan las condiciones materiales y simbólicas del comportamiento, al punto que sus creencias e intereses comprometen la utilidad pragmática de las conductas individuales y colectivas (Calsamiglia \& Tusón, 2008; Kabatek, 2008).

Ahora bien, si la descripción retrata los enunciados expresados de modo literal por los/las sujetos de estudio; la interpretación se centra en aquellos significados y sentidos 
deslizados, sugeridos o insinuados por razones históricas, culturales, sociales, políticas, ideológicas, económicas, religiosas, morales, etc. En términos metodológicos, las operaciones descriptivas evidencian las relaciones morfosintácticas y las reglas semánticas de las expresiones lingüísticas y acciones comunicativas, por lo que configuran-circunscriben sus condiciones de verdad en un campo objetivo, subjetivo e intersubjetivo. Y las operaciones interpretativas visibilizan los fines pragmáticos de aquello expresado y comunicado, por lo que regulan-normalizan-naturalizan su aplicabilidad en un contexto práctico y dialógico (Lizana, 2007, 2008, 2009).

Al respecto, se entiende dialogar como conversar, discutir, escuchar, comunicar, preguntar, responder y/o empalizar con ciertas formas de ser y estar en el mundo. Esta reflexión conjunta genera múltiples reacciones emotivas o un conjunto de repercusiones conceptuales, procedimentales y actitudinales entre la investigadora y los/las participantes. Que al ponerse en el lugar del otro/a o al reconocer(se) como un/a legítimo/a otro/a en la convivencia, se afectan, involucran e influyen mutuamente. Si bien las prácticas discursivas y no discursivas están hechas a la medida de sí mismo o expresan la cosmovisión propia y privilegiada de cada actor social, el diálogo como procedimiento metodológico implica respetar la coexistencia de múltiples puntos de vista. Lo que en un sentido positivo y amplio se entiende como la expresión legítima de la condición humana, un principio democrático, que incluye la locución tolerante de la diversidad y la conformación activa del Yo, Yo-Tú, Yo-Otro/a, Yo-Nosotros/as, Nosotros/as-Nosotros/as.

Por su parte, las operaciones analíticas procuran visibilizar un objeto de estudio mediante la (sub)división o (des)composición de sus ejes, elementos y procesos constitutivos. Según esta lógica comprensiva, las condiciones materiales y simbólicas de un contexto local y específico conforman la matriz significativa de sus expresiones lingüísticas y acciones comunicativas. Entonces, el análisis evidencia la (des)articulación y (dis)continuidad de las unidades morfológicas de los enunciados empleados, con las cosas dadas o manifiestas en su contexto de enunciación. Esta estrategia metodológica adopta distintos instrumentos analítico-sintéticos, a fin de recuperar los campos de experiencia de los actores sociales, y el carácter global y amorfo de sus estados de conciencia. Poniendo énfasis en cómo se estructura psíquica, comprensiva e interactivamente estas prácticas discursivas y no discursivas; o de qué manera se evidencian las modalidades externas, proposiciones de verdad y propiedades inherentes de sus relaciones simultáneas, corrientes o habituales (Daniel, 2002; Iñiguez, 2006; Calsamiglia \& Tusón, 2008; Kabatek, 2008).

En consecuencia, este estudio cualitativo se encuentra en directa sintonía con las operaciones metodológicas anteriormente expuestas, puesto que permiten describir, interpretar y analizar la complejidad de las experiencias humanas. Teniendo presente que su densidad depende del contexto histórico, cultural, social, político, ideológico, económico, religioso, lingüístico, etc. Por tales razones, la investigadora pretende recuperar la cosmovisión de los/las participantes mediante un hablar desde sí, con el propósito que cada persona pueda acercarse a los significados, valores o verdades coexistentes a sus campos de experiencia. Al respecto, se entiende que todo escenario de estudio está mediatizado, permeado o teñido por ciertos modos de (re)producción, distribución y aplicación del conocimiento; y por las formas de saber-ser, saber-conocer, saber-hacer y saber-convivir de sus comunidades.

Por lo tanto, esta investigación asume un enfoque participativo, colaborativo y dialógico, principalmente orientado a la transformación de los/las sujetos de estudio, 
en tanto comprendan y (de)construyan sus formas de ser y estar en el mundo. Lo que sugiere recuperar su voz y protagonismo como actores sociales, cuyo empoderamiento y emancipación adquiere relevancia cuando éstos toman decisiones reales y concretas en las distintas fases de la actividad indagativa. Por ello, se adopta una lógica inductiva, flexible y holística a lo largo de este estudio, a fin de evaluar la pertinencia de la perspectiva epistemológica, teórica y metodológica; y su coherencia con la definición del problema, preguntas y objetivos; con el diseño del trabajo de campo; con las estrategias de recolección y análisis del material de investigación; con los criterios de rigor científico; con la articulación de los hallazgos preliminares y finales, etc. (Eisner, 1998; Taylor y Bogdan, 1986; Hernández, Fernández, Baptista, 2006).

Además, la inducción se incluye como procedimiento metodológico en esta investigación, ya que se pretende conocer-aprehender-(re)construir la singularidad de un objeto de estudio, a partir de los marcos de referencia y campos de experiencia de sus actores protagónicos. Esta inferencia supone acceder lógicamente a las distintas formas de entendimiento, cuyas estructuras categoriales se describen, interpretan y analizan en términos contextuales, particulares u ocasionales. Del mismo modo, la flexibilidad se incorpora como una disposición positiva y abierta hacia la permanente (re)construcción de las actividades indagativas, por lo que cede, adapta o acomoda la continuidad de sus procesos, al compás de los cambios e imprevistos emergentes. Igualmente, lo holístico busca comprender la globalidad de los contextos y la complejidad de los/las participantes, dado que los componentes autorreguladores inciden en el carácter irreductible de su participación individual y colectiva (Taylor y Bogdan, 1986).

Por lo tanto, este estudio busca ampliar los campos de análisis de las expresiones lingüísticas y acciones comunicativas de los actores protagónicos de la Formación Docente Inicial. Entendiendo que en estas prácticas discursivas y no discursivas subyacen los significados, valores o verdades asociados a sus contextos y procesos formativos. Por ello, se ha optado por un procedimiento inductivo, flexible y holístico, a fin configurar el carácter no lineal, emergente e interactivo de su dimensión personal, social, formativa y profesional. Esta matriz significativa supone una totalidad de sentidos inexpresables, donde las condiciones de existencia y campos de (im)posibilidades sobre lo no dicho, permiten comprender el juego de coordinaciones, explicitas e implícitas, acerca de lo dicho. Un conjunto de premisas, que le exigen a la investigadora interactuar con los/las sujetos de estudio de manera natural, sensible, respetuosa y no intrusiva, experimentando la realidad tal como éstos/as la viven y haciéndose cargo de los efectos generados por su presencia. (Hernández, Fernández, Baptista, 2006).

Es más, estos procedimientos metodológicos pretenden recuperar las perspectivas de género de los/las sujetos de estudio, lo que implica exponerlas, discutirlas e interrogarlas, mediante un dialogo permanente, transparente y pluralista. De modo que las personas vislumbren los núcleos, límites, aristas y recovecos de estos puntos de vista; o tomen conciencia de la orientación ideológica y polifónica que habita en sus proposiciones. Para tales efectos, la investigadora utiliza el estudio colectivo de casos, por lo que examina detallada, comprensiva y sistemáticamente cómo un objeto de estudio emerge en su contexto local y específico. Este método de indagación procura describir, interpretar y analizar las particularidades y complejidades del caso en sí mismo, cuya riqueza, profundidad y densidad se manifiesta en situaciones naturales, cotidianas o habituales. (Pérez, 1998; Sandín, 2003). 
Al mismo tiempo, esta investigación pretende levantar múltiples esferas temáticas, puntos de (des)articulación y nudos problemáticos desde distintos escenarios de estudio, entendiendo que sus semejanzas o diferencias generalmente están asociadas a ciertas maneras de (re) producción, distribución y aplicación del conocimiento. La configuración heurística de estos saberes, habilidades y actitudes conforma la experiencia de conocer-aprehender-(re)construir de los actores sociales, por lo que ilumina su comprensión y disposición hacia las unidades de análisis del objeto de estudio. Por lo demás, el estudio colectivo de casos es un método activo, intensivo y profundo, que recupera la idiosincrasia, peculiaridad u originalidad de cada caso particular; e identifica, selecciona, contextualiza, justifica y compara su perspectiva extrínseca e intrínseca, con la del conjunto de casos que forma parte. Esta yuxtaposición epistemológica, teórica y metodológica se realiza mediante ciertas fases, procedimientos y actividades, las que de manera inductiva, flexible y holística sustentan los principios de esta práctica indagativa; el diseño e implementación del trabajo de campo; la descripción, interpretación y análisis de los hallazgos de investigación; y la elaboración del informe final. Para una mayor comprensión de estas ideas, se presenta el siguiente cuadro explicativo (Sandín, 2003):

Cuadro 1. Cuadro explicativo

\begin{tabular}{|c|c|c|}
\hline FASES & PROCEDIMIENTOS & ACTIVIDADES \\
\hline \multirow{2}{*}{$\begin{array}{l}\text { PREPARATORIA: } \\
\text { Principios } \\
\text { epistemológicos, } \\
\text { teóricos y } \\
\text { metodológicos } \\
\text { de las prácticas } \\
\text { indagativas. }\end{array}$} & $\begin{array}{l}1^{\circ} \text { Configuración del } \\
\text { Problema en estudio. }\end{array}$ & $\begin{array}{l}\text { A partir de la revisión y discusión bibliográfica, } \\
\text { documentar: } \\
\text {-- El Marco de Referencia del Problema en } \\
\text { estudio. } \\
\text {-- Los antecedentes contextuales del enfoque, la } \\
\text { justificación, las preguntas y los objetivos de la } \\
\text { problemática en estudio. }\end{array}$ \\
\hline & $\begin{array}{l}2^{\circ} \text { Configuración } \\
\text { de la perspectiva } \\
\text { epistemológica, } \\
\text { teórica y } \\
\text { metodológica del } \\
\text { estudio. }\end{array}$ & $\begin{array}{l}\text { A partir de la revisión y discusión bibliográfica, } \\
\text { documentar: } \\
\text {.- El Marco Teórico y Metodológico del } \\
\text { estudio. } \\
\text {.- La construcción de roles y funciones de } \\
\text { la investigadora y de los/las participantes; } \\
\text { las fases del estudio; los criterios de validez, } \\
\text { confiabilidad y éticos, etc. }\end{array}$ \\
\hline \multirow{3}{*}{$\begin{array}{l}\text { CONSECUTIVA: } \\
\text { Diseño e } \\
\text { implementación del } \\
\text { trabajo de campo. }\end{array}$} & $\begin{array}{l}1^{\circ} \text { Planificación del } \\
\text { Trabajo de Campo. }\end{array}$ & $\begin{array}{l}\text { A partir del estudio colectivo de casos: } \\
\text {.- Diseñar las estrategias de recolección y } \\
\text { análisis del material de investigación. } \\
\text {.- Establecer los criterios de selección de los/ } \\
\text { las sujetos y de los escenarios de estudio. }\end{array}$ \\
\hline & $\begin{array}{c}2^{\circ} \text { Entrada al } \\
\text { escenario de estudio }\end{array}$ & $\begin{array}{l}\text { - Negociar las condiciones para entrar a los } \\
\text { escenarios de estudio. } \\
\text {-- Seleccionar a los/las sujetos de estudio. } \\
\text {-- Implementar las estrategias de recolección } \\
\text { del material de investigación. }\end{array}$ \\
\hline & $\begin{array}{c}3^{\circ} \text { Retirada del } \\
\text { escenario de estudio. }\end{array}$ & $\begin{array}{l}\text { - Finalizar la recolección de la información. } \\
\text {-- Negociar las condiciones para salir de los } \\
\text { escenarios de estudio. }\end{array}$ \\
\hline
\end{tabular}




\begin{tabular}{|c|c|c|}
\hline \multirow{2}{*}{$\begin{array}{l}\text { ANALÍTICA: } \\
\text { Descripción, } \\
\text { interpretación y } \\
\text { análisis de los } \\
\text { hallazgos de } \\
\text { investigación. }\end{array}$} & $\begin{array}{l}1^{\circ} \text { Configuración } \\
\text { de las estrategias de } \\
\text { análisis del material } \\
\text { de investigación. }\end{array}$ & $\begin{array}{l}\text { A partir del análisis crítico del discurso textual, } \\
\text {.- Construir una matriz lógica, general } \\
\text { y específica, para darle una estructura y } \\
\text { organización a las prácticas discursivas de los/ } \\
\text { las sujetos de estudio. }\end{array}$ \\
\hline & $\begin{array}{l}2^{\circ} \text { Enmarcamiento } \\
\text { teórico - analítico } \\
\text { del material de } \\
\text { investigación. }\end{array}$ & $\begin{array}{c}\text {.- Describir, interpretar y analizar, } \\
\text { las expresiones lingüísticas, acciones } \\
\text { comunicativas y orientaciones ideológicas de } \\
\text { los sujetos de estudio. } \\
\text {.- Enmarcar los hallazgos de investigación con } \\
\text { la perspectiva teórico - analítica del estudio. }\end{array}$ \\
\hline \multirow{2}{*}{$\begin{array}{l}\text { INFORMATIVA: } \\
\text { Elaboración del } \\
\text { informe final. }\end{array}$} & $\begin{array}{l}1^{\circ} \text { Diseño del reporte } \\
\text { de investigación. }\end{array}$ & $\begin{array}{l}\text {.- Construir el formato o esquema del reporte } \\
\text { de investigación. } \\
\text {.- Actualizar los antecedentes contextuales del } \\
\text { Problema en estudio. } \\
\text {.- Fabricar el consolidado teórico - analítico de } \\
\text { los hallazgos de investigación. }\end{array}$ \\
\hline & $\begin{array}{l}2^{\circ} \text { Escritura del } \\
\text { informe final. }\end{array}$ & $\begin{array}{c}\text {.- Confeccionar las conclusiones y limitaciones } \\
\text { del estudio. } \\
\text {.- Construir las proyecciones y las nuevas } \\
\text { interrogantes. }\end{array}$ \\
\hline
\end{tabular}

Por consiguiente, el estudio colectivo de casos es esencialmente activo, ya que permite conocer-aprehender-(re)construir la matriz significativa de una realidad sociocultural, y combinar distintas visiones teórico-prácticas en el campo investigativo. Con objeto de comprender el significado de una experiencia, o la red de sentidos, valores o verdades asociadas al funcionamiento de sus ejes, elementos y procesos constitutivos. Estas consideraciones establecen el ciclo vital de un caso observado, o caracterizan la estructura organizacional de una comunidad institucional, a fin de ampliar el ámbito de sus relaciones materiales y simbólicas (Stake, 2007).

Con referencia a esta investigación, el estudio colectivo de casos intenta analizar una relación (in)visibilizada en los contextos de Formación Docente Inicial, una configuración de la Identidad Profesional Docente desde una perspectiva de género. Para ello, se describen, interpretan y analizan las prácticas discursivas y no discursivas de sus actores protagónicos, ya que sus dispositivos o ejes de poder; epistemes o ejes de saber; y parámetros éticos o estado de conciencia de sí y del otro/a, establecen las reglas socio-históricas de estas expresiones lingüísticas y acciones comunicativas. Al respecto, se entiende que la dimensión personal, social, formativa y profesional de dichos contextos y procesos formativos, configura las operaciones representacionales asociadas a la división sexual del trabajo y las experiencias identitarias relativas a las relaciones de género. Estos propósitos le exigen a la investigadora permanecer durante un periodo de tiempo en cada escenario de estudio, a fin de comprender cuáles son los ejes, elementos y procesos, que constituyen estas dimensiones; cuáles son sus modalidades externas, proposiciones de verdad y propiedades inherentes; cuáles son sus modos de saber-ser, 
saber-convivir, saber-conocer y saber-hacer; cuáles son sus procesos de subjetivación, objetivación e intersubjetivación; cómo se (des)articulan estas dimensiones y modos a lo largo de la formación, etc.

De igual manera, esta investigación busca (re)interpretar o (re)significar la estructura psíquica, comprensiva e interactiva de cada caso observado, para luego establecer relaciones más amplias con el conjunto de casos estudiados. Sin perder de vista que cada comunidad institucional comparte ciertos patrones culturales y pautas de comportamiento con otras colectividades, ya que pertenecen a un contexto histórico, cultural, social, político, económico, ideológico, etc. Por ello, la investigadora genera espacios de reflexión, individuales y grupales, para que los/las sujetos de estudio develen la red de sentidos, valores o verdades asociadas a sus circunstancias reales e imaginarias. En virtud que la voz del Yo, Yo-Tú, Yo-Otro/a, Yo-Nosotros/as, Nosotros-Nosotros/as lea los acontecimientos o hechos de su contexto; comprenda el significado de sus experiencias; y analice el estado de cosas buscando soluciones válidas y aceptables para su realidad. Estos encuentros próximos y sucesivos provocan múltiples repercusiones en las dinámicas humanas, lo que implica evidenciar los disensos y consensos (in)mediatos; o visibilizar la normatividad de ciertas esferas temáticas, puntos de (des)articulación y nudos problemáticos, comunes o recurrentes (Pérez, 1998; Sandín, 2003; Stake, 2007).

En definitiva, un trabajo de campo con estas características le permite a la investigadora problematizar o desnaturalizar los modos de saber-ser, saber-convivir, saber-conocer y saber-hacer de los/las sujetos de estudio. La recursividad y (dis)continuidad de estos intercambios, acrecientan y diversifican las modalidades externas, proposiciones de verdad y propiedades inherentes de la propia (re)conceptualización experiencial. Asimismo, esta investigación adopta una serie de decisiones en el corto, mediano y largo plazo, a fin de que su perspectiva macro contextualice los derechos y las obligaciones ciudadanas de los/ las participantes, y su perspectiva micro examine sus roles y funciones dentro de cada escenario de estudio. Esta vigilancia ontológica, epistemológica y metodológica configura el enfoque ideográfico de un caso en acción, cuyo valor formativo, significativo y sustantivo se fundamenta a partir de ciertos procesos de individualización y socialización.

Por tales razones, la investigadora configura las unidades de análisis del objeto de estudio a través de los significados y sentidos asociados a las prácticas discursivas y no discursivas de los/las participantes. A partir de la connotación y denotación de estos enunciados, se realiza un levantamiento de categorías descriptivas, interpretativas y analíticas, estableciendo una distinción operacional entre sus relaciones conceptuales, procedimentales y actitudinales. Este procedimiento metodológico busca asegurar la confiabilidad y validez de los hallazgos de investigación, entendiendo que la primera refiere a la solidez y equilibrio de las estrategias implementadas; y la segunda a la autenticidad y legitimidad de los resultados o productos alcanzados.

$\mathrm{Al}$ respecto, los criterios de confiabilidad describen la consistencia de las fases, procedimientos y actividades diseñadas a lo largo del estudio. Esta valoración por la calidad expresa la solidez y el equilibrio adoptado en las estrategias de recolección y análisis del material de investigación. La que permite evaluar sistemáticamente la pertinencia de los casos estudiados; la densidad y particularidad de las observaciones realizadas; y la riqueza de las aseveraciones y (pre)juicios formulados. Para evitar distorsiones o tergiversaciones por parte de la investigadora, los procesos descriptivos muestran con precisión, exactitud y transparencia un relato contextualizado sobre un objeto de estudio; los interpretativos 
evidencian la orientación ideológica, que habita o subyace en la denotación de sus significados y en la connotación de sus sentidos; y los analítico-sintéticos despliegan un modelo global y equilibrado sobre la comprensión de los mismos (Sandín, 2003; Flick, 2004; Hernández, Fernández \& Baptista, 2006).

Por su parte, los criterios de validez refieren a la veracidad o credibilidad de los hallazgos de investigación. Esta (re)construcción conjunta de saberes, habilidades y actitudes se fundamenta en las proposiciones de verdad o en el consenso de verdades de una comunidad institucional, por que opta por una presentación sintagmática y paradigmática. Para la primera se emplean las expresiones lingüísticas y acciones comunicativas de los/las sujetos de estudio como extractos medulares, citas textuales y/o ejemplos emblemáticos, a fin de categorizar o tipificar sus ideas clave. Y en la segunda se confronta o integra el cuerpo vertebral de estos productos, con ciertas formas de producción, distribución y aplicación del conocimiento. Ambas perspectivas sostienen la validez de constructo de los resultados alcanzados, haciendo inteligible el carácter discursivo de la (re)conceptualización experiencial (Sandín, 2003; Flick, 2004; Hernández, Fernández \& Baptista, 2006).

En consecuencia, esta investigación considera a la narración en sí misma como un objeto de valoración, ya que legitima los mecanismos de objetivación, subjetivación e intersubjetivación de los/las sujetos de estudio. Igualmente, se reconoce que la investigadora escribe y lee desde su propio bagaje cultural, lo que incide en sus maneras de problematizar la estructura y organización de la sociedad o condiciona sus formas de comprender las relaciones de poder dentro de una comunidad institucional. Esta incardinación ideológica se expresa con total transparencia en los contextos locales y específicos, o se comunica abiertamente en los encuentros colectivos e individuales, dado que se busca evidenciar los aspectos de dominación y autoritarismo en las interacciones humanas; y empoderar a los grupos desfavorecidos, haciendo patente sus necesidades, intereses y expectativas sobre la construcción cultural de la diferencia (Lizana, 2007, 2008, 2009).

Asimismo, este estudio considera las implicancias éticas del Yo como instrumento, lo que implica resguardar los derechos humanos del Sujeto-Investigadora y del Sujetoparticipante, durante la entrada y retirada del escenario de estudio. Al respecto, la responsabilidad, respeto, protección, libertad, autonomía, reciprocidad, confianza, entre otros, se entienden como principios orientadores de sus conversaciones individuales y colectivas; o son criterios reguladores de sus encuentros próximos y sucesivos. En tal sentido, se dispone de un consentimiento informado o código ético, a fin de comunicar a los/las sujetos de estudio, cuáles son las motivaciones, propósitos, implicancias, alcances y proyecciones de esta investigación. Por ello, estas personas firman un documento explicativo o un compromiso de confidencialidad, donde se explicita que los hallazgos de investigación serán utilizados con fines exclusivamente académicos y profesionales, garantizando su seguridad, privacidad e identidad.

Por lo tanto, las perspectivas epistemológicas, teóricas y metodológicas de esta investigación pretenden sumergirse en la dimensión personal, social, formativa y profesional de la Formación Docente Inicial. Con el objeto de indagar en las operaciones representacionales asociadas a la división sexual del trabajo y en las experiencias identitarias relativas a las relaciones de género, según los protagonistas de cada escenario de estudio. De manera explícita e implícita, este contexto local y específico participa en los procesos de subjetivación, objetivación e intersubjetivación, y se encuentra incardinado ideológicamente en tramas culturales de significación. Las que intervienen en la 
estructuración psíquica sobre las imágenes-apariencias-reacciones de sí mismo/a; en la estructuración comprensiva sobre los modos de saber-ser, saber-convivir, saber-conocer y saber-hacer; y en la estructuración interactiva sobre la matriz significa del contexto histórico y sociocultural. Si bien, la investigadora declara que no existe un método infalible para conocer-aprender-(re)construir la realidad. Ella opta por el estudio colectivo de casos porque sus principios valoran los elementos discursivos y no discursivos en sí mismos, y sus estrategias permiten diferenciar las esferas temáticas, puntos de (des)articulación y nudos problemáticos, tanto del caso observado como del conjunto de casos estudiados.

Cuadro 2. Análisis de una relación (in)visibilizada en los contextos de Formación Docente Inicial: Una reflexión epistemológica, teórica y metodológica desde una perspectiva de género

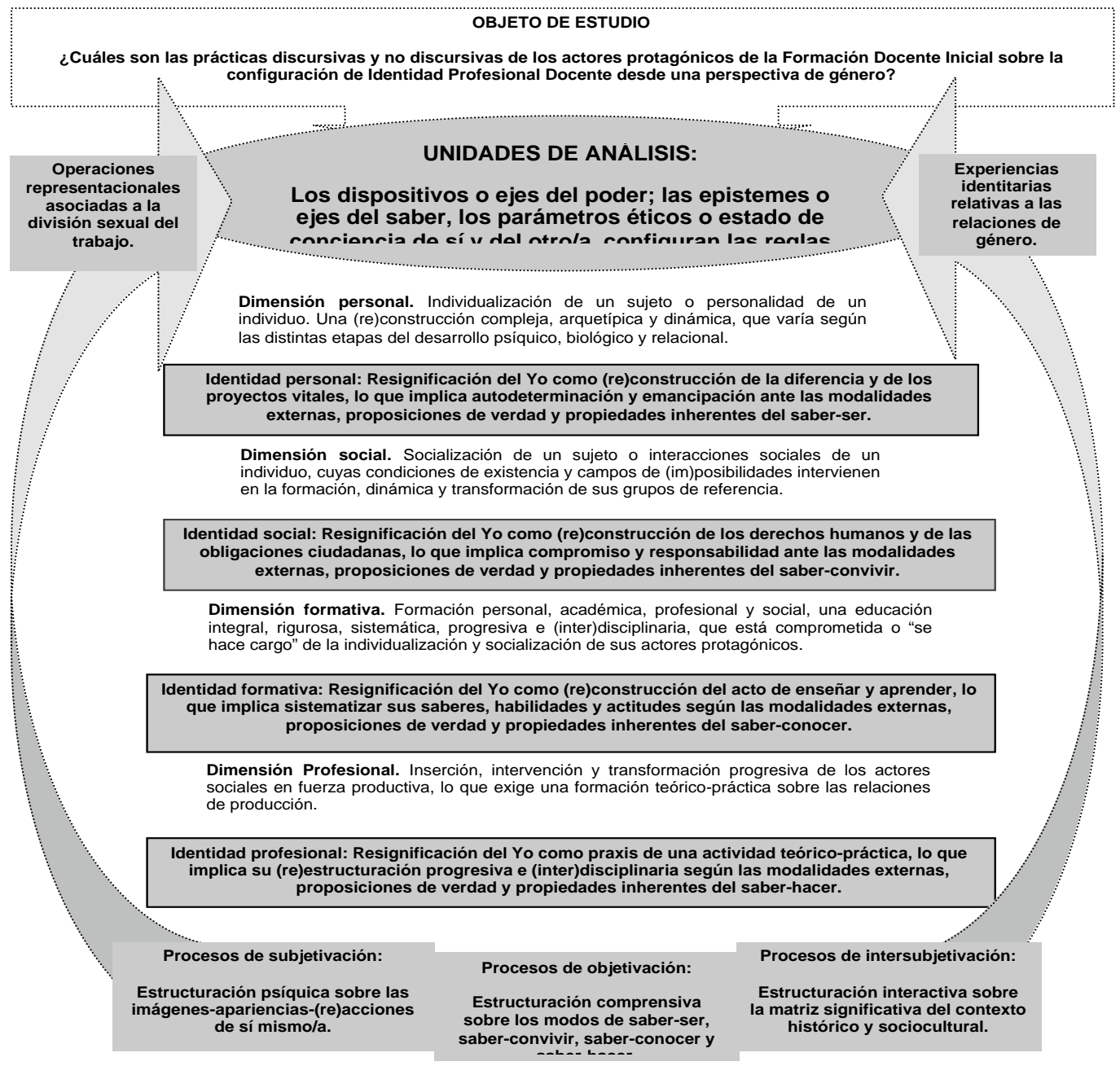




\section{REFERENCIAS BIBLIOGRÁFICAS}

Abbagnano, N. (2007). Diccionario de Filosofía. México: Fondo de Cultura Económica.

Aguerrondo, M. (2005). Grandes pensadores: historia del pensamiento pedagógico occidental. Buenos Aires: Papers Editores.

Amorós, C. (1991). Hacia una crítica de la razón patriarcal. Barcelona: Anthropos Editorial Ltda. Beauvoir, S. (1965). El segundo sexo. I los hechos y los mitos. Buenos Aires: Ediciones Siglo Veinte. Bernal, A., Zúñiga, H. (2007). Metodología de la investigación para administración, economía, humanidades y ciencias sociales. Viña del Mar: Universidad del Mar.

Bernard, M. (1997). Introducción a la lectura de la obra de René Kaës. Buenos Aires: Ediciones Publikar.

Bisquerra, R. (2004). Metodología de la Investigación Educativa. Madrid: Morata.

Bolívar, A. (2007). Educación para la ciudadanía. Madrid: Editorial Graó.

Bourdieu, P. (2000). La Dominación Masculina. Barcelona: Editorial Anagrama S.A.

Bunge, M. (1978). La Ciencia, su método y su filosofía. Buenos Aires: Siglo Veintiuno.

Butler, J. (2002). Cuerpos que importan. Sobre los limites materiales y discursivos del "sexo". Buenos Aires: Editorial Paidós SAICF.

Butler, J. (2006). Deshacer el género. Madrid: Editorial Paidós Ibérica S.A..

Cárdenas, A. (2001). Estudio comprensivo del discurso de estudiantes de pedagogía: su voz y el proceso de formación docente. Tesis de Magíster en Investigación Educativa. Santiago: Universidad Academia de Humanismo Cristiano.

Calsamiglia, H. Tusón, A. (2008) Las cosas del decir: manual de análisis del discurso. Madrid: Editorial Ariel S.A.

Castro, E. (2004). El vocabulario de Michel Foucault. Un recorrido alfabético por sus temas, conceptos y autores. Buenos Aires: Universidad Nacional de Quilmes.

Cherryholmes, C. (1999). Poder y crítica. Investigaciones postestructurales en educación. Barcelona: Pomares-Corredor. S.A.

Consuegra, N. (2010). Diccionario de psicología. Bogotá: ECOE Ediciones.

Corbetta, P. (2007). Metodología y técnicas de investigación social. Madrid: McGrawHill.

Daniel, G. (2002). Investigación cualitativa y análisis crítico del discurso en educación. Perspectivas teóricas y estrategias metodológicas. Catamarca: Universidad Nacional de Catamarca.

De Gialdino, V. (1992). Métodos cualitativos: los problemas teórico-metodológicos. Buenos Aires: Centro Editor de América Latina.

Dewey, J. (2008). El arte como experiencia. Madrid: Editorial Paidós Ibérica. S. A.

Eisner, E. (1998). El ojo ilustrado: indagación cualitativa y mejora de la práctica educativa. Madrid: Ediciones Paidós Ibérica S.A.

Flick, U. (2004). Introducción a la investigación cualitativa. Madrid: Morata.

Foucault, M. (2006). La Arqueología del saber. Argentina. Buenos Aires: Siglo XXI Editores, S.A. Fraser, N. (1997). Iustitia interrupta: reflexiones críticas desde la posición "postsocialista". Bogotá: Siglo del Hombre Editores - Universidad de los Andes.

Giroux, H. (2004). Teoría y resistencia en educación: una pedagogía para la oposición. Buenos Aires: Siglo XXI Editores Argentina S.A.

Giroux, H. (2006). La escuela y la lucha por la ciudadanía: pedagogía crítica de la época. Buenos Aires: Siglo XXI Editores Argentina S.A.

Harnecker, M. (2007). Los conceptos elementales del materialismo histórico. Buenos Aires: Siglo XXI Editores Argentina S.A.

Harré, R. Roger, L. (1992). Psicología social y de la personalidad. Buenos Aires: Ediciones Paidós SAICF.

Hernández, R., Fernández, C., Baptista, P. (2006). Metodología de la investigación. México: Editorial McGraw Hill. 
ANÁLISIS DE UNA RELACIÓN (IN)VISIBILIZADA EN LOS CONTEXTOS DE FORMACIÓN DOCENTE INICIAL:

UNA REFLEXIÓN EPISTEMOLÓGICA, TEÓRICA Y METODOLÓGICA DESDE UNA PERSPECTIVA DE GÉNERO

Iñiguez, L. (2006). Análisis del discurso. Manual para las ciencias sociales. Santiago: Editorial UOC. Irigaray, L. (2007). Espéculo de la otra mujer. Madrid: Ediciones AKAL S.A.

Kabatek, J. (2008). Sintaxis histórica del español y cambio lingüístico: nuevas perspectivas desde las tradiciones discursivas. Madrid: Iberoamericana Editorial.

Lamas, M. (1996). El género: la construcción cultural de la diferencia sexual. México: UNAM. Coordinación de Humanidades. Programa Universitario de Estudios de Género.

Lamas, M. (1998). Para entender el concepto de género. Quito: Ediciones Abya - Yala.

Lamas, M. (2002). Cuerpo: diferencia sexual y género. Ann Arbor, MI: Taurus - Universidad de Michigan.

León, O. y Montero, I. (2002). Métodos de investigación en psicología y educación. Madrid: McGraw Hill.

Lizana, V. (2007). Representaciones sociales sobre masculinidad, feminidad, heterosexualidad y homosexualidad de los/las estudiantes de pedagogía, en contextos de Formación Docente Inicial. Tesis de Magíster en Estudios de Género mención Humanidades. Santiago: Universidad de Chile.

Lizana, V. (2008). Representaciones sociales sobre feminidad de los/las estudiantes de pedagogía, en los contextos de Formación Docente Inicial. Estudios Pedagógicos, vol. XXXIV, 2, 115-136. Disponible en http://www.scielo.cl/scielo.php?pid=S0718-07052008000200007\&script=sci_arttext

Lizana, V. (2008). Representaciones sociales sobre masculinidad de los/las estudiantes de pedagogía, en los contextos de Formación Docente Inicial. Revista Electrónica Iberoamericana sobre Calidad, Eficacia y Cambio en Educación, vol. 6, n. 1, 134-153. Disponible en http://www. rinace.net/arts/vol6num1/art8.pdf

Lizana, V. (2009). Una relación invisibilizada en los contextos de Formación Docente Inicial: La identidad profesional desde una perspectiva de género. Revista Iberoamericana sobre Calidad, Eficacia y Cambio en Educación, vol. 7, n. 3, 70-81. Disponible en http://www.rinace.net/ reice/numeros/arts/vol7num3/art5.pdf

Lizana, V. (2009) Representaciones sociales sobre heterosexualidad y homosexualidad de los/ las estudiantes de pedagogía, en los contextos de Formación Docente Inicial. Estudios Pedagógicos, vol. XXXV, n. 1, 117-138. Disponible en http://www.scielo.cl/scielo. php?pid=S0718-07052009000100007\&script=sci_arttext

Mialaret, G. (1984). Diccionario de Ciencias de la Educación. España: Oikos-tau. S.A. Ediciones.

Molina, P. (2001). La identidad profesional y la formación inicial de profesores. Una posibilidad de profesionalización docente. Enunciación, n. 6, 80-84. Disponible en http://revistas.udistrital. edu.co/ojs/index.php/enunc/article/view/2447/3397

Molina, P. (2005). Identidad profesional docente construidas por estudiantes de Educación General Básica durante su Formación Inicial una mirada desde las actividades de práctica formativa. Tesis de Doctorado en Ciencias de la Educación. Santiago: Pontificia Universidad Católica de Chile.

Montecinos, S. (1999). Género y epistemología. Mujeres y disciplinas. Santiago: LOM Ediciones. Neri, C. (1997). Manual de psicoanálisis de grupo. Buenos Aires: Ediciones Nueva Visión SAIC. Pérez, G. (1994). Investigación cualitativa: Retos e Interrogantes. Madrid: Ediciones La Muralla. Volumen 1: Métodos

Pérez, G. (1994). Investigación cualitativa: Retos e Interrogantes. Madrid: Ediciones La Muralla. Volumen 2: Técnicas y análisis de datos.

Pozo, J. Scheuer, N. (2006). Nuevas formas de pensar la enseñanza y el aprendizaje: las concepciones de profesores y alumnos. Madrid: Editorial Graó.

Rawls, J. (2002). La justicia como equidad: una reformulación. Madrid: Ediciones Paidós Ibérica. Rawls, J. (1998). Teoría de la justicia. Madrid: Fondo de Cultura Económica.

Ruiz, J. (1999). Metodología de la investigación cualitativa. Bilbao: Universidad de Deusto. Rodríguez, M. (2003). La metamorfosis del cambio educativo. Madrid: Ediciones AKAL. Sandín M. (2003). Investigación Cualitativa en Educación. Madrid: Ediciones Mc Graw Hill. Stake, R. (2007). Introducción con estudio de caso. Madrid: Ediciones Morata S.L. 
ANÁLISIS DE UNA RELACIÓN (IN)VISIBILIZADA EN LOS CONTEXTOS DE FORMACIÓN DOCENTE INICIAL: UNA REFLEXIÓN EPISTEMOLÓGICA, TEÓRICA Y METODOLÓGICA DESDE UNA PERSPECTIVA DE GÉNERO

Steinberg, R. Talburt, S. (2005). Pensando 'queer'. Sexualidad, cultura y educación. Madrid: Editorial Graó.

Stenhouse, L (1998). La investigación como base de la enseñanza. Madrid: Ediciones Morata.

Taylor, S. y Bogdan, R. (1986). Introducción a los Métodos Cualitativos de Investigación. Buenos Aires: Editorial Paidós.

Trilla, J. (2007) El legado pedagógico del Siglo XX para la escuela del Siglo XXI. Madrid: Editorial Graó.

Wodak, R., Meyer, M. (2003). Métodos de Análisis Crítico del Discurso. Barcelona: Editorial Gedisa S.A. 
